\title{
Rosuvastatin, inflammation, C-reactive protein, JUPITER, and primary prevention of cardiovascular disease - a perspective
}

This article was published in the following Dove Press journal:

Drug Design, Development and Therapy

9 December 2010

Number of times this article has been viewed

\section{Richard Kones}

The Cardiometabolic Research Institute, Houston, TX, USA
Correspondence: Richard Kones, MD.

Cardiometabolic Research Institute,

8I8I Fannin St, U3| 4 Houston,

TX 77054, USA

$\mathrm{Tel}+17137909100$

Fax +I 7137909292

Email drrkones@comcast.net
Abstract: The major public health concern worldwide is coronary heart disease, with dyslipidemia as a major risk factor. Statin drugs are recommended by several guidelines for both primary and secondary prevention. Rosuvastatin has been widely accepted because of its efficacy, potency, and superior safety profile. Inflammation is involved in all phases of atherosclerosis, with the process beginning in early youth and advancing relentlessly for decades throughout life. C-reactive protein (CRP) is a well-studied, nonspecific marker of inflammation which may reflect general health risk. Considerable evidence suggests CRP is an independent predictor of future cardiovascular events, but direct involvement in atherosclerosis remains controversial. Rosuvastatin is a synthetic, hydrophilic statin with unique stereochemistry. A large proportion of patients achieve evidence-based lipid targets while using the drug, and it slows progression and induces regression of atherosclerotic coronary lesions. Rosuvastatin lowers CRP levels significantly. The Justification for Use of statins in Prevention: an Intervention Trial Evaluating Rosuvastatin (JUPITER) trial was designed after the observation that when both low density lipoprotein and CRP were reduced, patients fared better than when only LDL was lowered. Advocates and critics alike acknowledge that the benefits of rosuvastatin in JUPITER were real. After a review, the US Food and Drug Administration extended the indications for rosuvastatin to include asymptomatic JUPITER-eligible individuals with one additional risk factor. The American Heart Association and Centers of Disease Control and Prevention had previously recognized the use of CRP in persons with "intermediate risk" as defined by global risk scores. The Canadian Cardiovascular Society guidelines went further and recommended use of statins in persons with low LDL and high CRP levels at intermediate risk. The JUPITER study focused attention on ostensibly healthy individuals with "normal" lipid profiles and high CRP values who benefited from statin therapy. The backdrop to JUPITER during this period was an increasing awareness of a rising cardiovascular risk burden and imperfect methods of risk evaluation, so that a significant number of individuals were being denied beneficial therapies. Other concerns have been a high level of residual risk in those who are treated, poor patient adherence, a need to follow guidelines more closely, a dual global epidemic of obesity and diabetes, and a progressively deteriorating level of physical activity in the population. Calls for new and more effective means of reducing risk for coronary heart disease are intensifying. In view of compelling evidence supporting earlier and aggressive therapy in people with high risk burdens, JUPITER simply offers another choice for stratification and earlier risk reduction in primary prevention patients. When indicated, and in individuals unwilling or unable to change their diet and lifestyles sufficiently, the benefits of statins greatly exceed the risks. Two side effects of interest are myotoxicity and an increase in the incidence of diabetes.

Keywords: rosuvastatin, JUPITER study, statin drugs, C-reactive protein, dyslipidemia, cholesterol, primary prevention, cardiovascular risk, coronary heart disease, inflammation, low-density lipoprotein, high-density lipoprotein, diabetes, metabolic syndrome, Framingham risk score, Reynolds risk score, coronary artery calcification, carotid intima-media thickness, hypertension, obesity, HMG CoA reductase, mevalonate, prenylation, statin myopathy, pleiotropic, dolichol

\section{Introduction}

Cardiovascular disease (CVD) has been the leading cause of death for the past century in the United States (US), except for 1918, the year of an influenza pandemic. Even though 
deaths from coronary heart disease (CHD) have fallen during the past 2 decades, the mortality rate from this disease remains the top cause of death in the US, and, by 2020, will attain that status globally as well. An analysis of the fall in CHD death rates from 1980 to 2000 using the IMPACT model of analyzing data from the US National Center for Health Statistics ${ }^{1,2}$ revealed that half of this decline was due to improvements in risk factors; $79 \%$ was attributable to primary prevention and $21 \%$ to secondary prevention. ${ }^{3}$ Cholesterol reduction accounted for $42.7 \%$ of the death rate reduction in asymptomatic individuals, and for 34\% in those with CHD. Use of statin drugs accounted for $<20 \%$ of the improvement in death rate during those 20 years. Reductions in systolic blood pressure accounted for $38.8 \%$ of the fall in asymptomatic individuals and $52.8 \%$ in patients with CHD. Decreased use of tobacco accounted for $18.4 \%$ of the fall in deaths in asymptomatic individuals, and $12.9 \%$ in those with CHD. While the contribution of statins, 3-hydroxy-3-methyl-glutaryl-coenzyme A reductase (HMGR) inhibitors, was surprisingly small, these results illustrate the power of primary prevention in the management of CHD. Given the lower usage of less potent statins in many of the years surveyed, the data simultaneously suggest that using statin drugs earlier in the disease, for longer periods of time during pathogenesis, and titrated to lower targets, has substantial unrealized potential.

The cardiovascular risk burden in the populations of nearly all countries continues to rise at an alarming rate, and recent analyses show that gains in reducing the death rate from $\mathrm{CHD}$ are now being offset by the pressure of increases in reversible factors of obesity, ${ }^{4}$ metabolic syndrome, and diabetes, along with the progressive aging of the population. ${ }^{5-8}$ Control of risk factors, while impressive thus far, have also fallen short of guideline targets and public health goals. Hence, there is ongoing interest in the best use of all elements of primary prevention in order to improve national heart health. Statin drugs are uniquely effective and prominently recommended in current guidelines. The potency and favorable benefit to risk ratio of rosuvastatin account for its increasing usage in primary and secondary prevention.

Significant and voluminous research concerning the biochemistry, physiology, and clinical potential of measuring C-reactive protein (CRP), has intensified discussions concerning the role CRP monitoring will have in current guidelines for primary prevention. The Justification for the Use of Statins in Primary Prevention: an Intervention Trial Evaluating Rosuvastatin (JUPITER) trial, first reported in October 2008, presented evidence that a plasma $\mathrm{CRP} \geq 2 \mathrm{mg} / \mathrm{L}$ reflects higher cardiovascular risk in asymptomatic individuals with low-density lipoprotein levels (LDL) $<130 \mathrm{mg} / \mathrm{dL}$, and that they would benefit from rosuvastatin therapy. ${ }^{9}$ Following the JUPITER report, there was lively debate about the data, clinical significance, and how the new information should be incorporated into clinical practice. Many fundamental questions concerning primary prevention have since been revisited, including the early beginnings of CHD and its long incubation period; methods of evaluating risk in the population; how populationbased versus individual risk-based approaches may best be employed; role and refinement of global risk factor scores; choice and merits of nontraditional risk factors; assessment of multiple biomarker panels; role of imaging techniques in evaluation and ongoing therapy; value of advanced lipid testing; weights assigned to traditional risk factors, cutoff values, and treatment targets, particularly LDL goals in guidelines; use of statins in primary prevention; reasons for low patient adherence with evidence-based therapies; causes of "clinical inertia" and lack of physician compliance with guidelines; and the etiologies, extent, and minimization of residual risk.

\section{C-reactive protein}

The fundamental role of inflammation in the pathogenesis of atherothrombotic disease is based upon strong evidence and is well-accepted. ${ }^{11-61} \mathrm{CRP}$ protein is an acute phase reactant discovered by Tillett and Francis at Rockefeller University in 1930 in the blood of patients with pneumonia, ${ }^{62}$ was crystallized in 1947, and today, over 60 years later, there is still controversy about its physiology and applications in biomedicine. CRP protein is a pentraxin comprised of 5 subunits (Figure 1) which is primarily synthesized in the liver, and plays an active part in regulating the innate immune system. Since CRP mRNA levels rise in adipose tissue as CRP expression is enhanced in vitro by interleukin-6 (IL-6), adipose cells also have some ability to synthesize CRP. Innate immunity and adaptive immunity significantly modulate atherosclerosis, ${ }^{13,63,64}$ with both pro- and anti-atherogenic potential. ${ }^{64-66}$

CRP binding offers a glimpse into teleological function. CRP binds to phosphocholine, commonly found in cell membranes as well as in bacterial and fungal polysaccharides. Phosphocholine is used by the placenta and nematodes to cloak them from their host immune system. Binding to complement C1q complex and factor H, CRP assists in human complement activity to promote antigen presentation and phagocytosis, ${ }^{67}$ essentially functioning as an innate opsonin. In addition, CRP binds directly with phagocyte Fc $\gamma$ receptors, ${ }^{68}$ literally becoming the interface between innate immunity, C1q on complement, and inflammation, Fc $\gamma$ on macrophages. Details of CRP binding to its ligands and their 
implications have been recently reviewed.$^{53}$ As an acute phase reactant during infections or diffuse tissue destruction, CRP concentrations may increase 50,000-fold quickly. ${ }^{69} \mathrm{~A}$ constant potent stimulus may sustain high circulating CRP concentrations, depending upon synthetic capacity; the half-life of CRP in the circulation is about 19 hours. ${ }^{70}$ Hepatic synthesis is driven at the transcriptional level by IL-6, largely expressed by macrophages, T cells, and adipocytes. ${ }^{11,71}$ Several upstream cytokines also regulate hepatic CRP release. In part because there is overlap in signaling, plasma CRP values are related to other inflammatory markers. However, despite a plethora of research, the precise role(s) of CRP remain unclear.

\section{Variation and significance of CRP levels}

Baseline values of CRP are influenced by genetics. ${ }^{72,73}$ Even after correction for age, $C R P$ polymorphisms, and smoking, ancestry affects CRP levels, the highest values being found in blacks, with an average of $2.6 \mathrm{mg} / \mathrm{L}$, followed by Hispanics, $2.51 \mathrm{mg} / \mathrm{L}$, South Asians, $2.34 \mathrm{mg} / \mathrm{L}$, whites, $2.03 \mathrm{mg} / \mathrm{L}$, and East Asians with the lowest level at $1.01 \mathrm{mg} / \mathrm{L} .{ }^{74} \mathrm{CRP}$ levels also vary with the environment, eg, pollutant burdens $;{ }^{75}$ fiber intake, ${ }^{76-79}$ coffee ingestion, ${ }^{80}$ and other dietary factors; ${ }^{26,29,81-84}$ smoking; ${ }^{85}$ body mass index ${ }^{86,87}$ alcohol consumption; ${ }^{88,89}$ drugs, including contraceptives ${ }^{90}$ and hormone replacement therapy $;{ }^{91}$ chronic infections, ${ }^{92,93}$ and noninfectious inflammatory conditions, such as the autoimmune diseases,${ }^{94-97}$ cancer, ${ }^{98}$ and polycystic ovary syndrome; ${ }^{99-102}$ as well as multiple risk factors for atherosclerosis, including obesity, diabetes, metabolic syndrome, and hypertension. Triage of patients according to CRP levels generally control, correct for, and consider these variations.

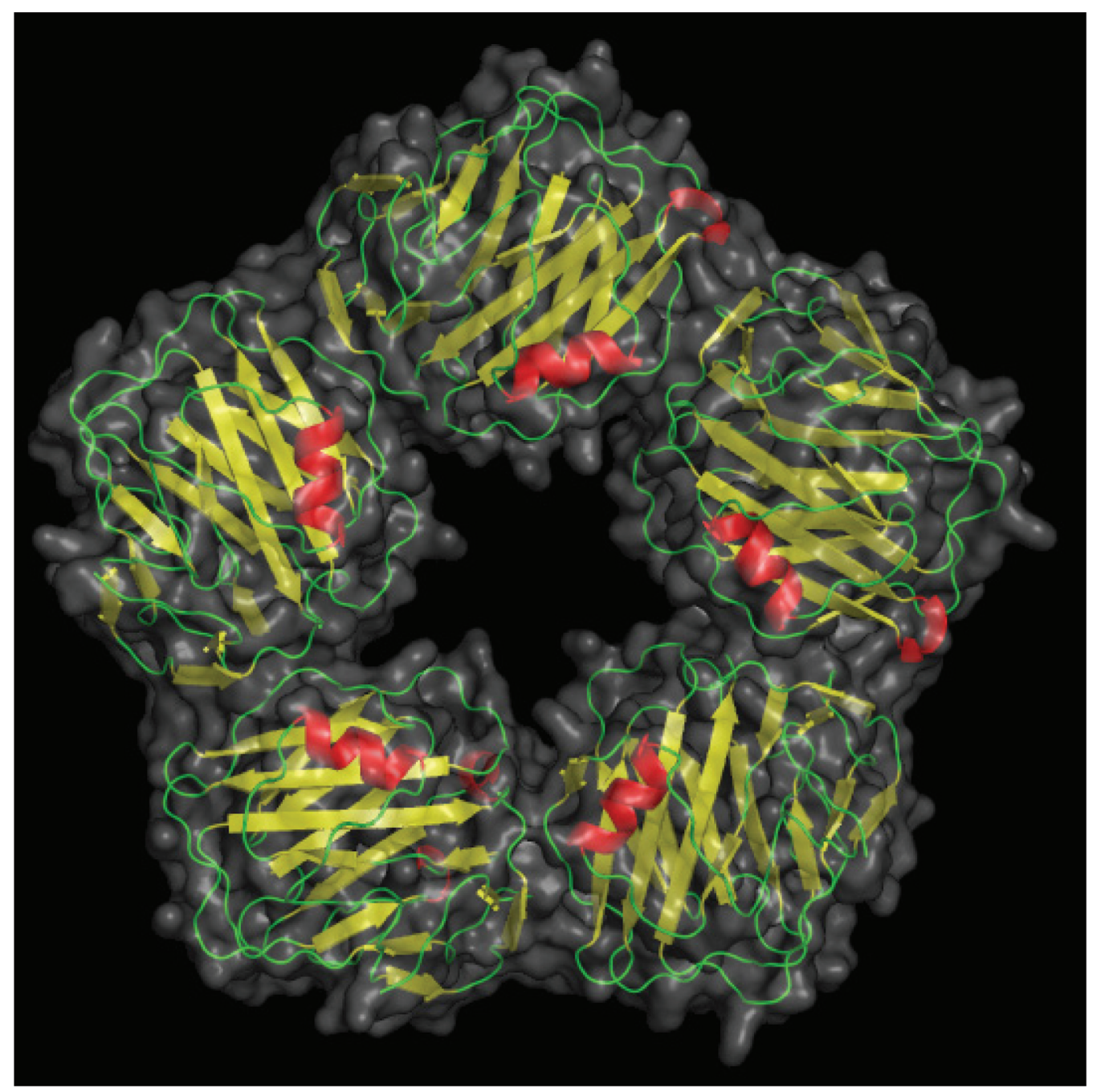

Figure I A picture of C-reactive protein (CRP) from IB09.pdb made using pymol. ${ }^{10} \mathrm{CRP}$ is a pentameric molecule containing a recognition face that binds phosphocholine and calcium ions, and on the opposite side, an effector face that contains a $\mathrm{Cl}$ q-binding site. Function depends upon $\mathrm{Ca}^{2+}$-dependent ligand binding. See text for details. Reproduced by permission of Skolstoe through Wikipedia commons. 
Since CRP binds to LDL and can be identified within atherosclerotic plaque, ${ }^{103,104}$ is involved with inflammatory atherogenic processes, ${ }^{105-116}$ is elevated in patients with acute (ACS) and chronic coronary syndromes ${ }^{117-120}$ with unfavorable plaque compositions in these syndromes, ${ }^{55}$ and is associated with complications of heart failure ${ }^{121}$ a causal role in atherothrombotic disease has long been suspected. At this time, causality remains unproven. ${ }^{107,122,123}$ One intriguing property of CRP is the associated inhibition of endothelial nitric oxide synthase in vitro ${ }^{124}$ and the relationship to impaired vasoreactivity and hypertension in such models. ${ }^{125}$ Overall, the evidence for a role of CRP in endothelial cell dysfunction and monocyte activation in metabolic syndrome is impressive and difficult to ignore. ${ }^{126}$ The prevalence of this syndrome is approaching $53 \%$ in some populations (excluding those with diabetes) $)^{127}$ and the importance of endothelial dysfunction in pathogenesis is now unassailable. ${ }^{128}$

It is generally appreciated that a high CRP level (hereafter meaning hs-CRP [hs, highly sensitive] measurements) usually portends a poorer prognosis in patients with CHD, diabetes, hypertension, pre- or postoperative surgery, and vascular comorbidities. A high prevalence of elevated circulating CRP levels in the general population has been known for some time. At the 53rd Annual Scientific Session of the American College of Cardiology, data were presented from the 1999-2000 National Health and Nutrition Examination Survey (NHANES) indicating that $47.1 \%$ of respondents aged 20 years or over had high CRP values. ${ }^{129,130}$ Levels were higher in females, the obese, and in the elderly, aged 55 to 74. About one-third of the population has CRP levels above $3 \mathrm{mg} / \mathrm{L} .{ }^{131}$ However, smaller elevations in CRP are even more common, and over half of the population has a CRP $\geq 2 \mathrm{mg} / \mathrm{L}$. ${ }^{132}$ Such "minor" elevations in CRP also imply a poorer prognosis compared with lower values, both in the ill and the apparently healthy. ${ }^{133}$ Raised values of CRP strongly suggest clinical attention is necessary. Common associations of CRP elevations may reflect not only inflammation but widespread tissue distress, degeneration, and/ or destruction, much of which may be age-related. At the other end of the continuum, a low CRP has been considered a measure of wellness, ${ }^{134}$ and as lifestyle becomes progressively unhealthy in a population, CRP rises. As shown in the Monitoring Trends and Determinants in Cardiovascular Disease (MONICA) Augsburg Study, negative behaviors and factors, such as a poor quality "Western" diet with low intake of vegetables, fruits, and fiber, high consumption of saturated fats, poor physical fitness, and overfeeding and obesity, are all associated with higher CRP levels. ${ }^{135}$ In a global sense, when no overt disease is evident, the CRP level roughly follows the level of self-inflicted abuse. In these instances CRP elevations reflect poor lifestyle choices that lead to deranged metabolic signaling, inflammation, and the appearance and worsening of traditional risk factors during the early incubation period of atherosclerosis. As such, elevations tend to cluster with conventional risk factors, and teasing apart the significance has been difficult, ${ }^{136}$ but studies confirm that the properties of CRP and significance of changes are different. Lifestyle has a greater influence on CRP than does genetics. ${ }^{137}$ Conversely, sustained improvement in lifestyle, particularly weight loss with exercise, and measures that relieve the risk burden, including statins, all reduce plasma CRP levels.

In a review of hospital records of 22,962 patients in a large urban population, an analysis of change in CRP status normal $(\leq 3 \mathrm{mg} / \mathrm{L})$ to elevated $(>3 \mathrm{mg} / \mathrm{L})$ and vice versa - and mortality, revealed a significant graded association between CRP levels and mortality. ${ }^{138}$ The patients were not healthy or chosen at random, but rather a cohort selected by physicians who believed their patients needed a CRP level performed. A change from normal to elevated CRP levels within a year was associated with a 6.7-fold hazard ratio (HR) for all-cause mortality during the following 4 years, compared to subjects whose CRP remained normal. When CRP levels changed from elevated to normal, the HR halved to 3.5. In the hospital setting as well, CRP levels reflect risk and subsequent survival, with a strong relationship to all-cause mortality, particularly in vascular diseases and cancer. ${ }^{139}$

In the elderly, high CRP values are associated with greater risk of all-cause mortality, especially in apolipoprotein E4 carriers, as well as with cognitive decline. ${ }^{140}$ The Rancho Bernardo Study reported that the lower the circulating CRP level in elderly men, the greater their longevity, and plasma concentrations of IL-6 were inversely related to survival time in elderly women who did not use estrogen. ${ }^{141}$ Finally, the classic paper that showed CRP was a stronger predictor of cardiovascular events than LDL, and measuring both together provided better prognostic information than screening for either alone, firmly established the potential clinical significance of following circulating CRP concentrations. ${ }^{142}$ This study also demonstrated the inverse relationship between CRP levels and the probability of event-free survival.

The work cited above supports the significance of circulating CRP levels in "ordinary" individuals as a sensitive but nonspecific index of quality of lifestyle prior to the diagnosis of disease, as a screen for risk refinement beyond traditional risk factors, and as an index that reflects the intensity of either the amount of inflammation or volume of cell distress. ${ }^{133}$ 
When CRP was compared to other inflammatory markers as a predictor of relative risk of hard coronary events (postmenopausal women, highest versus lowest quartile) relative risk scores were CRP, 4.4, serum amyloid A, 3.0, soluble intercellular adhesion molecule type 1, 2.6, IL-6, 2.2, total cholesterol, 2.4, LDL, 2.4, apolipoprotein B-100, 3.4, high-density lipoprotein (HDL), 0.3 , and for the ratio total cholesterol/HDL, 3.4. ${ }^{35}$ The predictive power of CRP remained significant for $\mathrm{LDL}$ values $<130 \mathrm{mg} / \mathrm{dL}$. Of all nontraditional risk factors, CRP is the most studied, with over 34,000 general PubMed results, and 12,500 in connection with CVD, authored by investigators around the world over an extended period of time. CRP is involved in basic pathophysiology, and/or reflects additional risk and/or has predictive power in a number of CVDs, equivalents, or comorbidities, which include hypertension, ${ }^{143-151}$ hypertension and blood pressure variability, ${ }^{152}$ percutaneous coronary intervention, ${ }^{153,154}$ re-endothelialization, ${ }^{110}$ stent implantation, ${ }^{155}$ coronary artery bypass surgery, ${ }^{156-158}$ heart failure, ${ }^{159-167}$ peripheral arterial disease, ${ }^{168,169}$ carotid artery disease, ${ }^{170}$ sudden cardiac death (SCD), ${ }^{171-173}$ atrial fibrillation, ${ }^{174-176}$ ventricular tachycardia after myocardial infarction (MI) and implantable cardioverter-defibrillator implantation, ${ }^{177}$ calcific aortic valve disease, ${ }^{178}$ venous thromboembolism, ${ }^{179,180}$ pulmonary arterial hypertension, ${ }^{181}$ diabetes, ${ }^{116,182-186}$ metabolic syndrome, ${ }^{87,93,168,180,185,187-199}$ rheumatic mitral stenosis, ${ }^{200}$ chronic lung disease and asthma, ${ }^{201-203}$ chronic kidney disease, ${ }^{154,204-206}$ obstructive sleep apnea, ${ }^{207-208}$ air pollution vis-à-vis inflammation and cardiac risk, ${ }^{75,209,210}$ obesity, ${ }^{137,197,211-223}$ eclampsia, ${ }^{224}$ blood concentrations of reactive oxygen species, ${ }^{225}$ depression in the obese, ${ }^{211}$ depression associated with coronary artery disease, ${ }^{226}$ and HIV disease progression. ${ }^{225}$ Statins have been found useful in many of these clinical situations. The preponderance of the evidence, from many diverse sources, indicates that CRP measurement has significant broad-based value and is also uniquely related to vascular disease.

\section{CRP and genetic studies}

$C R P$ genetic (pentraxin-related) polymorphisms exist, which, together with diet and other lifestyle factors, contribute to significant interindividual variation in plasma CRP levels, as well as differences in responses to therapeutic agents. ${ }^{227}$ Such variants in the CRP locus may account for 30\% to $50 \%$ of the phenotypic variation in CRP levels, ${ }^{228}$ and may also explain some ethnic differences. ${ }^{229} \mathrm{CRP}$ concentrations are $16 \%$ lower, for instance, in Asians, but 26\% higher in black people than in whites. ${ }^{230}$ In addition, other genetic loci that encode for upstream cytokines (IL-6, IL-1, tumor necrosis factor $\alpha$ ) that affect CRP synthesis influence CRP levels, as well as genes related to obesity and insulin resistance. ${ }^{187}$

Mendelian randomization, the random assortment of genes that occurs during reproduction, provides a method for assessing cause and effect that is not influenced by reverse causation. ${ }^{231-233}$ By comparing natural variation in known genes and phenotype, strengths of environmental influences may be inferred. ${ }^{234} \mathrm{~A}$ large genome-wide association $(n=17,967)$ and replication study $(n=13,615)$ examined the association of genetic loci with plasma CRP concentrations and risk of CHD. ${ }^{235}$ The authors found that genetic variants expected to lower the CRP expression by about $20 \%$ did not reduce CHD risk by the predicted amount of $6 \%$. The discordance between anticipated versus actual CRP phenotype argued that, in genetic variants, high CRP levels throughout life do not cause increased risk for ischemic heart disease. Several limitations to the study, and in the use of Mendelian randomization generally, were identified. ${ }^{236}$ Another Mendelian randomization study of 47,000 individuals from the general population revealed a comparable situation elsewhere: high plasma CRP values were robustly associated with higher risk of atrial fibrillation, but not with genetically elevated CRP levels. ${ }^{176}$

\section{Causation versus predictive utility}

The Emerging Risk Factors Collaboration (ERFC) reported a meta-analysis of records of 160,309 people with medical histories of vascular disease, associating $\log _{\mathrm{e}} \mathrm{CRP}$ concentrations with conventional risk factors and inflammatory markers. ${ }^{237}$ Their data confirmed that downstream markers of inflammation, especially fibrinogen levels, but also the leukocyte count, plasma albumin concentration, and erythrocyte sedimentation rate, were associated with CRP levels. As the investigators adjusted for conventional risk factors, the associations of CRP levels with risk of CHD weakened, but the most significant adjustment was for fibrinogen perturbations during inflammation. Hepatic synthesis of this protein is also regulated by IL- 6 . Hence, the ERFC concluded that most of the association of CRP with coronary artery disease depends upon conventional risk factors and fibrinogen levels. ${ }^{18,238-240}$ Their views are consistent with findings using Mendelian randomization discussed above, noting a disparity between $C R P$-related phenotypes, coronary risk, and subsequent coronary events.

Interestingly, after adjusting for conventional risk factors, the relative risks for CHD in this meta-analysis were CRP, 1.37, non-HDL cholesterol, 1.28, and systolic blood pressure, 1.35. Therefore, despite the conclusion, their data 
actually confirmed that CRP concentrations have a significant predictive association with risk of CHD, stroke, and vascular and nonvascular mortality.

While the ERFC appears to argue against a causative role of CRP in atherosclerosis, the issue is far from settled, since there is much convincing basic science that requires specific refutation. ${ }^{126}$ In addition, a significant putative role for the monomeric form of CRP (mCRP) has been proposed. ${ }^{241}$ Mediated by activated platelets, formation of $\mathrm{mCRP},{ }^{242}$ a conformationally distinct isoform which is prothrombotic ${ }^{243}$ and inflammatory, ${ }^{244}$ might confound conclusions if monomeric conversion of CRP from the pentameric moiety (pCRP) - commonly measured as hs-CRP - were not considered. Indeed, it has been shown that mCRP localizes monocyte-mediated inflammation in the atherosclerotic plaque, and may be deposited in plaques but not in healthy vessels, whereas pCRP is not found in either healthy or diseased arteries. ${ }^{244}$ Moreover, mCRP and pCRP have differing actions on neutrophil migration and thrombus evolution. The various metabolic roles of $\mathrm{pCRP}$ and $\mathrm{mCRP}$ are expertly reviewed in an editorial accompanying the aforementioned paper. ${ }^{115}$ There is further evidence that mCRP inserts into lipid raft microdomains within endothelial cell membranes, rather than binds to surface proteins, as a complex function of membrane cholesterol content. The result of this incorporation is endothelial cell activation, as part of an early inflammatory step in the atherosclerotic process. ${ }^{245}$ These data are but a small part of the burgeoning scientific literature that underscores the importance of CRP in atherothrombosis, and the need for further research.

A randomized trial using a drug that targets $\mathrm{CRP}$ will be necessary to decide whether or not CRP is causally involved in atherogenesis. However, even if proof of CRP participation in the atherothrombotic process is incomplete, separate evidence indicates that measurement of CRP levels is useful in predicting and monitoring particular groups of patients. For instance, AFCAPS-TexCAPS found that patients with higher CRP may anticipate a better response to statins, ${ }^{246}$ and selection of patients with high CRP levels in different circumstances adds to absolute risk assessment. ${ }^{142,247,248} \mathrm{As}$ mentioned above, the ERFC, a large meta-analysis, reported a consistent 1.6-fold rise in vascular risk for each 1-SD rise in CRP levels. ${ }^{237}$

After de Beer reported that elevations in CRP levels predicted a poor outcome after MI, ${ }^{249}$ baseline levels were found to predict future cardiac events in stable and unstable angina. ${ }^{250,251}$ These observations were extended to people without heart disease in whom baseline CRP measurements also correlated with future cardiac prognosis. ${ }^{135,252}$ Lowering CRP concentrations in patients without elevations in LDL following statin administration improved prognosis. ${ }^{248,253}$ Reporting bias, with multiple ways of comparing CRP values, together with publication bias in CRP studies, may hamper full evaluation of prognostic capability. ${ }^{254}$ Several studies confirm that patients with higher CRP levels are at greater risk than those with lower values. ${ }^{118,255}$ These data support the view that measurement of CRP improves prediction of risk. ${ }^{118,256}$ Another approach, as suggested by the American Heart Association, the CDC, and the Canadian Cardiovascular Society, is that patients with heart disease falling in the "intermediate risk" category - with a Framingham Risk Score (FRS) of $10 \%$ to $20 \%$ - have increased CHD risk if CRP levels are elevated, and may be considered for statin therapy. The Canadian Cardiovascular Society recommends prophylactic statins for men $>50$ years and women $>60$ years with a CRP level $>2 \mathrm{mg} / \mathrm{L}$, and who are otherwise considered "intermediate risk". ${ }^{257}$ Prior to the JUPITER study, ${ }^{9}$ considerable data showed that CRP levels $\geq 2 \mathrm{mg} / \mathrm{L}$ significantly raised risk, but currently laboratory reports continue to mention that CRP levels 2 to $3 \mathrm{mg} / \mathrm{L}$ reflect an average risk, and levels $>3 \mathrm{mg} / \mathrm{L}$ reflect greater than average risk. ${ }^{258}$ Large prospective cohort studies reported age-adjusted relative risks for coronary artery disease from about 2.0 to 3.0 for the highest versus the lowest levels of CRP, again documenting a consistent association with heart disease that has predictive power. ${ }^{12,86,259}$

Some studies report that CRP does not discriminate sufficiently, ${ }^{260,261}$ adds little to traditional risk factors, ${ }^{86}$ in particular the FRS, and hence may lack cost-effectiveness. On the other hand, investigators have reported remarkable discrimination in a number of clinical settings, ${ }^{255}$ have found that when CRP is added to existing risk evaluation systems predictive power is enhanced, ${ }^{256,262-268}$ and reported that cost-effectiveness is indeed significant. ${ }^{269-271}$ All things considered, CRP is admittedly imperfect, as are all risk factors. However, it is much better than other nontraditional risk factors when used to refine risk, particularly when used along with traditional risk factors. In conclusion, CRP is an acknowledged sensitive marker of systemic inflammation, ${ }^{11}$ and in primary prevention, over 40 reports from prospective studes and 2 meta-analyses report a consistent association of CRP with subsequent CHD events. ${ }^{86,272,273}$ One evolving view is that traditional risk factors and scores should be used initially, and CRP measured in patients at intermediate risk or in complex patients. If elevated, a more aggressive therapeutic stance may be warranted. 
Although lifestyle measures and some pharmacological agents do reduce CRP levels, statins are most frequently employed, and lower CRP levels about $15 \%$ to $35 \% .{ }^{274,275}$ Rosuvastatin and atorvastatin in higher doses have the most significant CRP-lowering properties. ${ }^{274}$

\section{Rosuvastatin}

The word cholesterol derives from the Greek chole- (bile), stereos (solid), and -ol, the chemical suffix for alcohol. First identified in gallstones in 1769, the modern name was begun by chemist Eugène Chevreul in 1815. By 1971 Japanese biochemist Akira Endo began seeking compounds to lower cholesterol, and in 1987 Merck began marketing lovastatin isolated from Aspergillus terreus.

The endogenous biosynthesis of cholesterol occurs through the mevalonate pathway (Figure 1). HMGR is a highly regulated enzyme which catalyzes the rate-limiting step in cholesterol synthesis. Although HMGR is located within membranes of the endoplasmic reticulum, its catalytic domain remains active after it is cleaved from the transmembrane portion of the enzyme. The reduction of HMG to mevalonic acid involves the transfer of 4 electrons, using 2 molecules of nicotinamide adenine dinucleotide (NADPH) as a reductant in 2 steps. The carboxyl moiety of hydroxymethlyglutarate esterified to the thiol of CoA is first reduced to an aldehyde, and then to an alcohol. Statin drugs are highly efficient competitive inhibitors of HMGR.

\section{Clinical pharmacology}

Rosuvastatin (Figure 3) is a sulfur-containing, hydrophilic statin with multiple sites that form a strong interaction with HMGR and therefore provide more potent enzyme inhibition than other statins. Stereochemical details of the molecular binding between rosuvastatin and HMGR have been detailed elsewhere. ${ }^{276,277}$ Rosuvastatin, like other statins, is a competitive antagonist of HMGR, competing directly with the endogenous substrate for the active site cavity of the enzyme. Rosuvastatin employs a modified hydroxyglutaric acid moiety that mimics the 3-hydroxyglutaryl unit of the substrate, HMG CoA, and the mevaldyl CoA transition state intermediate. The pyrimidine ring in rosuvastatin binds tightly to the HMGR enzyme in the same area that normally binds the CoA component of the endogenous substrate HMG CoA. As a synthetic, "type 2", or second-generation statin, rosuvastatin contains a fluorophenyl group which provides additional polar interactions that strengthen binding to HMGR. All told, rosuvastatin has an affinity for

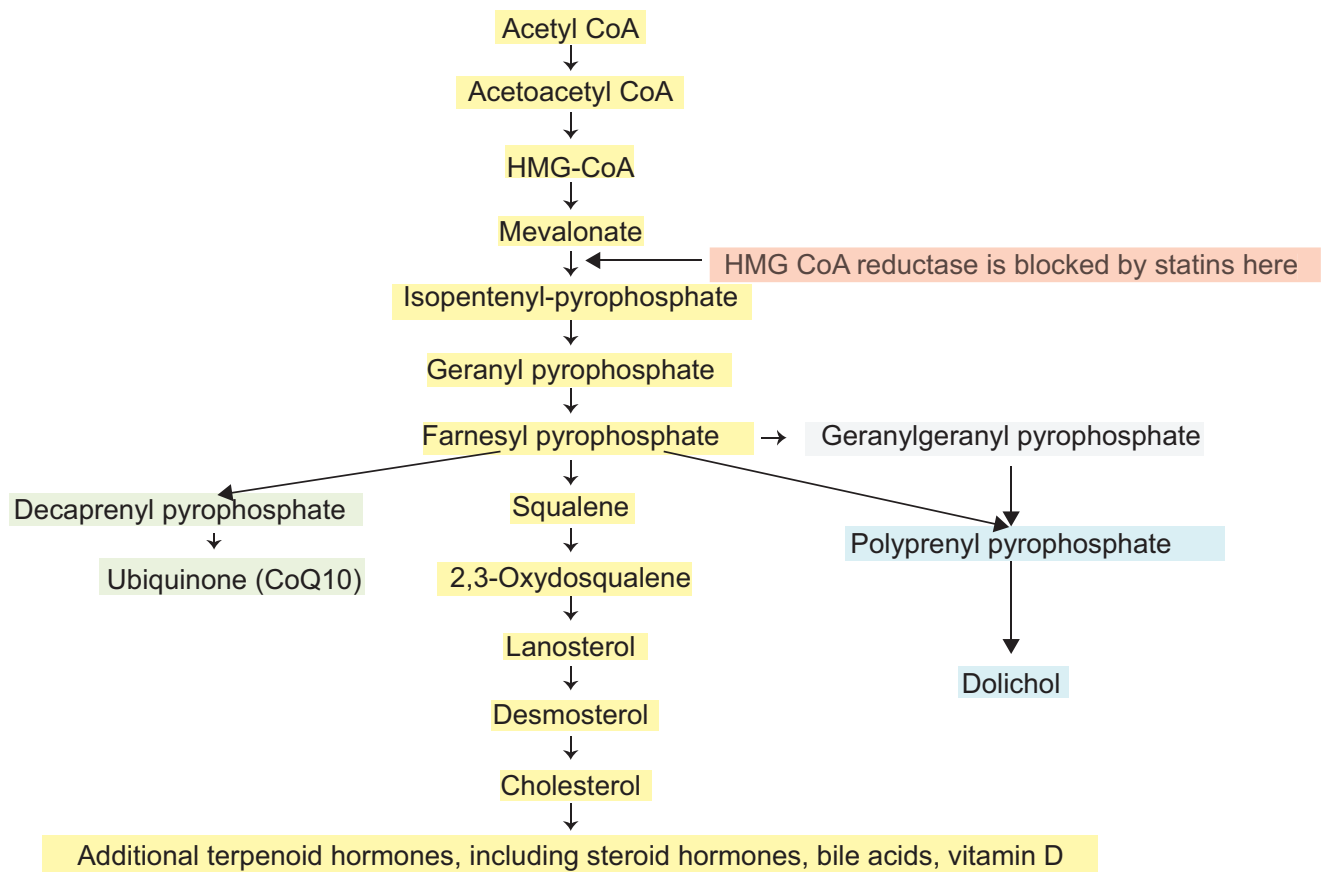

Figure 2 Cholesterol is synthesized via the mevalonate pathway. Acetyl-CoA forms 3-hydroxyl-3-methylglutaryl CoA (HMG-CoA) in several steps. The conversion of 3-hydroxy-3-methylglutaryl (HMG)-CoA to mevalonate, the rate-limiting step in cholesterol synthesis, is catalyzed by HMG-CoA reductase (HMGR), an enzyme within the endoplasmic reticulum. Rosuvastatin is an efficient competitive inhibitor of HMGR, reducing not only mevalonate levels, but also prenylated downstream products. The post-translational process of prenylation is needed for the function of small G proteins, including geranylgeranylation of Rho, Ras, and Rab, necessary for cellular signaling, transduction, and intermembrane translocation. As beneficial as statins are, there are obligatory molecular consequences inherent in their use, some related to their beneficial pleiotropic actions, but also to their side effects. Many steps and enzymes are omitted for clarity. 
the HMGR active site that is $>10^{4}$-fold higher than that of HMG CoA.

Rosuvastatin is administered in its active acid form, meaning that the pharmacophore binding to the HMGR needs no transformation for activity compared with simvastatin or lovastatin, which are administered as lactones, a portion of which is hydrolyzed to the active acid form. Rosuvastatin is a hydrophilic statin, with relatively greater hepatoselectivity due to a unidirectional carrier-mediated active transport system. Hydrophilic statins tend to be retained in the liver, in part because they cannot passively diffuse out, whereas lipophilic statins concentrate in nonhepatic tissues. This property of hydrophilic statins is believed to account for fewer adverse events. ${ }^{278,279}$ As a result, rosuvastatin joins fluvastatin and pravastatin among statins least likely to produce myotoxicity.

Peak plasma concentration $\left(\mathrm{C}_{\max }\right)$ is reached 3 to 5 hours after oral administration, ${ }^{280}$ and both $\mathrm{C}_{\text {max }}$ and the area under the plasma concentration-time curve (AUC) increase almost linearly with the dose. Absolute bioavailability is about $20 \%$. Rosuvastatin is $88 \%$ bound to plasma proteins, chiefly albumin. Mean volume of distribution under steady-state conditions is $\approx 134 \mathrm{~L}$. The half-life of rosuvastatin is 19 hours, the longest of the available statins. While pharmacokinetics do not differ meaningfully among white, Hispanic, or black individuals, Asians have about double the median exposure $\left(\mathrm{C}_{\max }\right.$ and $\left.\mathrm{AUC}\right)$ than whites. As a result, lower starting doses are advised in Asian-Americans.

Elimination is primarily in the liver, with $\approx 10 \%$ through the action of cytochrome CYP2C9, producing a metabolite, $\mathrm{N}$-desmethyl rosuvastatin, having up to half the potency of rosuvastatin. After oral administration, $90 \%$ of rosuvastatin and its metabolites are excreted in the feces. Following an intravenous dose, about $72 \%$ of total body clearance is via the hepatic route, and $28 \%$ through the kidneys. Lipophilic

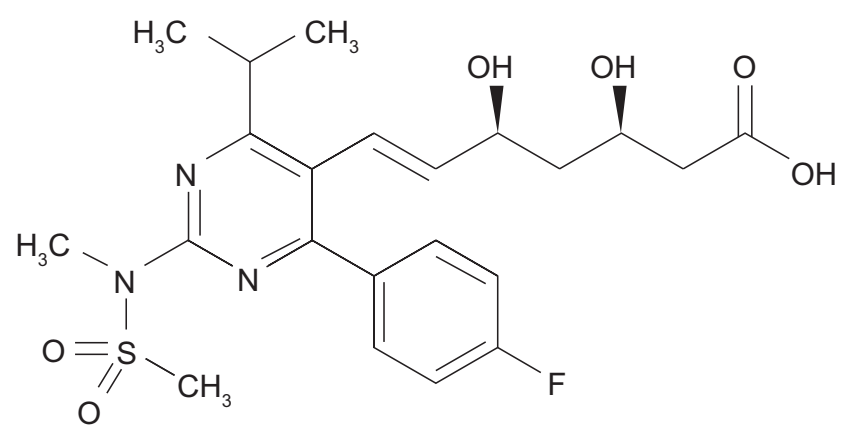

Figure 3 The structure of rosuvastatin, uniquely containing sulfur, a fluorophenyl group, and a modified hydroxyglutaric acid moiety. The IUPAC name of rosuvastatin is (E,3R,5R)-7-[4-(4-fluorophenyl)-2-[methyl(methylsulfonyl)amino]-6-propan2-ylpyrimidin-5-yl]-3,5-dihydroxyhept-6-enoic acid. statins must be metabolized to water-soluble forms for renal excretion, reactions that depend upon CYP450 isoenzymes. Compared to atorvastatin and some other statins, rosuvastatin has an advantage, since it is not metabolized predominantly through CYP3A4, eliminating many potential drug and food interactions. There are, however, other variables affecting pharmacokinetics and potential dose-related toxicity. P-glycoprotein (P-gp, also called ABCB1), an intestinal ATP-dependent drug efflux pump located in epithelial plasma membranes, prevents cellular uptake of xenobiotic foreign substances. P-gp also transports a number of endogenous biochemicals and drugs across cell membranes, noteably digoxin, and is inhibited by several statins. Available data do not indicate that rosuvastatin inhibits P-gp significantly, and therefore interactions with P-gp substrates and inhibitors, many of which are also CYP3A4 interactants, are not clinically relevant. Another potential interaction involves a hepatic uptake transporter, organic anion transporting polypeptide 1B1 (OATP1B1). ${ }^{281}$ Cyclosporine and gemfibrozil are OATP1B1 inhibitors, which may explain coadministration interactions. ${ }^{282}$ (See further discussion below under Side effects).

For each $39 \mathrm{mg} / \mathrm{dL}(1 \mathrm{mmol} / \mathrm{L})$ fall in LDL, there is a $21 \%$ reduction in major cardiovascular events. ${ }^{283}$ Atorvastatin lowers LDL up to $60 \%$ at a maximal dose of $80 \mathrm{mg}$. Rosuvastatin lowers LDL by $45 \%$ to $63 \%$ (5 mg, $38 \% ; 10 \mathrm{mg}, 43 \%$; $20 \mathrm{mg}, 48 \%$; $40 \mathrm{mg}$, 53\%; $80 \mathrm{mg}, 58 \%$ ), reduces triglyceride levels by $10 \%$ to $35 \%$, and raises HDL by $8 \%$ to $14 \% .{ }^{179,284}$ The rise in HDL is believed to be due to a combination of a lower apolipoprotein A-1 (apoA-1) catabolism, raised hepatic apoA-1 synthesis, peroxisome proliferator-activated receptor- $\alpha$ activation and inhibition of cholesteryl ester transfer protein. ${ }^{280}$ Of all the statins, rosuvastatin has the lowest half maximum inhibitory concentration for cholesterol synthesis in the liver. The milligram-equivalent reductions in LDL and elevations in HDL are superior to those of other statins, ${ }^{179}$ thereby achieving evidence-based LDL targets in a higher portion of patients and greater success during intensive LDL reduction (Table 1). Rosuvastatin also lowers small, dense LDL concentrations. Although the reductions in LDL are dose-related, increasing the dose beyond $10 \mathrm{mg}$ generally produces progressively smaller absolute reductions in LDL levels per unit.

\section{Clinical studies with rosuvastatin}

The Galaxy Program ${ }^{285}$ is a long-term, multi-trial research initiative sponsored by AstraZeneca, a planned portfolio of studies to investigate and support use of rosuvastatin to 
improve cardiovascular events and outcomes. The JUPITER study is one component, among others such as ASTEROID, METEOR, and CORONA. JUPITER sought to determine whether $20 \mathrm{mg}$ of rosuvastatin could lower the number of major cardiovascular events in patients with acceptable LDL (under current guidelines) and elevated CRP levels, using a combined end point of death, MI, stroke, unstable angina or revascularization, and is further described below.

The Measuring Effects on Intima-Media Thickness: an Evaluation of Rosuvastatin (METEOR) trial randomized 984 asymptomatic participants with a mean age of 57 years, FRS $<10 \%$, modest carotid intima-media thickness (CIMT) thickening (1.2 to $<3.5$ ), and elevated LDL (mean, $154 \mathrm{mg} / \mathrm{dL}$ ) to either rosuvastatin $40 \mathrm{mg}$ or placebo. ${ }^{286,287}$ The primary end point was the annualized rate of change in maximum CIMT at 12 sites during the 2-year study period. The rate of progression of maximum CIMT was significantly reduced by rosuvastatin therapy, but actual lesion regression was not achieved.

The Controlled Rosuvastatin Multinational Trial in Heart Failure (CORONA) was conducted from 2003 to 2005 in 371 sites in 21 countries. $^{288}$ The study randomized 5011 patients $\geq 60$ years of age with chronic New York Heart Association (NYHA) class II, III, or IV ischemic systolic heart failure and an ejection fraction less than $40 \%$ to either rosuvastatin $10 \mathrm{mg}$ or placebo. Median follow up was 32.8 months. There was a sharp fall in mean LDL $(137 \mathrm{mg} / \mathrm{dL})$ and CRP (3.1 mg/dL) at baseline to 3-month values of 76 and 2.1 respectively. The primary end point of the study was a composite of cardiovascular-related death, nonfatal MI, and nonfatal stroke. Secondary outcomes were total and cardiovascular mortality, time to first coronary event, and number of hospitalizations. By the end of the follow-up period, almost one-third of the participants sustained one end point event. There was no significant effect of rosuvastatin on primary or secondary end points, but a subsequent analysis suggested that those with CRP $\geq 2.0$ had a $13 \%$ relative risk reduction and better outcomes. ${ }^{289}$ The Gruppo Italiano per lo Studio della Sopravvivenza nell'Infarto Miocardico Heart Failure (GISSI-HF) trial, which took place at 357 medical facilities in Italy, also prospectively randomized 4574 patients with NYHA class II-IV heart failure to rosuvastatin $10 \mathrm{mg}$ or placebo, without an improvement in the primary end point. ${ }^{290}$ In GISSI-HF the event rate was similarly high, with over half the patients sustaining a cardiovascular death or hospitalization, reporting a $29 \%$ all-cause mortality during a follow-up of over 4 years. Although no explanation was forthcoming, it is apparent that these patients were quite ill with well advanced structural changes and pathophysiology. A recent commentary hypothesized that progression beyond a critical threshold in the pathogenesis of heart failure may have precluded any beneficial effect, citing the need for additional trials. ${ }^{291}$

Likewise, in A Study to Evaluate the Use of Rosuvastatin in Subjects on Regular Hemodialysis: An Assessment of Survival and Cardiovascular Events (AURORA), 2776 patients with end-stage chronic renal disease (ESRD) at 284 dialysis facilities in 25 countries were randomized to rosuvastatin $10 \mathrm{mg}$ or placebo, and there was no significant difference between groups in a primary end point of time to a major cardiovascular event, even though LDL and CRP levels were substantially reduced in the treatment group. ${ }^{292}$ In this population the event rate of MI, stroke and cardiovascular death was $>35 \%$, again reflecting complex, advanced disease and extremely high absolute risk. One author proposed that in both ESRD and calcific aortic stenosis, once disease has progressed sufficiently, particularly with anatomical changes, statins may become unable to help achieve the end points chosen. ${ }^{293}$ When begun earlier during aortic sclerosis or mild stenosis, improvement is more likely than when stenosis is advanced. In ESRD, since cardiovascular mortality rises sharply by the time a patient requires dialysis, the threshold for benefit may have been passed prior to enrolling in the study.

The results of the A Study to Evaluate the Effect of Rosuvastatin on Intravascular Ultrasound-Derived Coronary Atheroma Burden (ASTEROID) study offer insight into the effects of rosuvastatin on the atherosclerotic process using two different, complementary techniques. First, monotherapy with $40 \mathrm{mg}$ rosuvastatin for 24 months, which lowered LDL and raised HDL by about $53 \%$ and $15 \%$ respectively,

Table I Rough equivalent doses of rosuvastatin

\begin{tabular}{lllllll}
\hline \% Reduction in LDL & Rosuvastatin & Atorvastatin & Simvastatin & Fluvastatin & Lovastatin & Pravastatin \\
\hline $30-40$ & $5 \mathrm{mg}$ & $10 \mathrm{mg}$ & $20 \mathrm{mg}$ & $80 \mathrm{mg}$ & $40 \mathrm{mg}$ & $40 \mathrm{mg}$ \\
$40-45$ & $5-10 \mathrm{mg}$ & $20 \mathrm{mg}$ & $40 \mathrm{mg}$ & N/A & $80 \mathrm{mg}$ & $80 \mathrm{mg}$ \\
$46-50$ & $10-20 \mathrm{mg}$ & $40 \mathrm{mg}$ & $80 \mathrm{mg}$ & N/A & N/A & N/A \\
$50-55$ & $20 \mathrm{mg}$ & $80 \mathrm{mg}$ & N/A & N/A & N/A & N/A \\
$56-60$ & $40 \mathrm{mg}$ & N/A & N/A & N/A & N/A & N/A
\end{tabular}

Abbreviation: LDL, low-density lipoprotein. 
significantly reduced atheroma volume in major coronary arteries that were angiographically normal or were stenosed, as assessed with intravascular ultrasound. ${ }^{294}$ Second, using quantitative coronary angiography (QCA), rosuvastatin decreased percentage diameter of coronary stenoses and improved minimum lumen diameter. ${ }^{295}$ Intravascular ultrasound images the coronary artery wall in proximal areas with minimal lumen stenosis, and QCA examines luminal narrowing in different segments of the coronary tree. Concordance of the findings strongly suggests rosuvastatin causes both slowing of progression of atherosclerosis and lesion regression in concert with LDL levels $\leq 70 \mathrm{mg} / \mathrm{L}(1.81 \mathrm{mmol} / \mathrm{L})$. Reduction of luminal diameter, as detected by QCA, correlates with lower risk of future coronary events ${ }^{296}$ and subsequent mortality. ${ }^{297}$ Interestingly, changes in atheroma volume, when stratified above or below a median change of $-37.1 \%$ in LDL and $-21.4 \%$ in CRP levels, was greatest in those with reductions in both LDL and CRP $\left(-2 \mathrm{~mm}^{3}\right)$, less when CRP fell but not LDL $\left(-1 \mathrm{~mm}^{3}\right)$, progressed when LDL fell but CRP was high $\left(+2 \mathrm{~mm}^{3}\right)$, and progressed the most when both LDL and CRP were high $\left(+8 \mathrm{~mm}^{3}\right) .{ }^{294}$

\section{The JUPITER study}

Based upon (a) the ability of CRP to predict future vascular events, ${ }^{142,299-301}$ and (b) of statins to lower CRP, ${ }^{301}$ together with (c) additional evidence that the benefits of statins were greater when both LDL and CRP levels were lowered, ${ }^{249,253}$ and (d) a post-hoc analysis of the AFCAPS/TExCAPS study that indicated that healthy individuals with elevated CRP levels and normal LDL values could benefit from statin therapy, ${ }^{246}$ the global, multicenter JUPITER study was designed. ${ }^{9,302,303}$ After screening some 90,000 prospects, JUPITER enrolled 17,802 men ( $\geq 50$ years) and women ( $\geq 60$ years). The study population was not diagnosed with either CHD or diabetes, and had "normal" LDL levels (LDL $<130 \mathrm{mg} / \mathrm{dL})$, but high hs-CRP levels $(\geq 2.0 \mathrm{mg} / \mathrm{L}$, median, $4.2 \mathrm{mg} / \mathrm{L}$ ).

Participants were randomized to either treatment with rosuvastatin $20 \mathrm{mg}$ daily or placebo. Participants' median age was 66 years, and they comprised $62 \%$ men, $38 \%$ women, $71 \%$ Caucasians, $12.5 \%$ blacks, and $12.7 \%$ Hispanics (Table 2). Although free from clinical illness, the JUPITER population was not healthy, with $41 \%$ qualifying for the metabolic syndrome cluster of risk factors, $16 \%$ using tobacco, and $11.5 \%$ with a family history of premature heart disease. The cohort was fairly representative of the general population, with as-yet undetected, but substantial risk burden. This is an important point, since sometimes the term "healthy" may automatically be interpreted to mean "no treatment is necessary".

The primary end point composite included a nonfatal MI, nonfatal stroke, hospitalization for unstable angina, an arterial revascularization procedure, or confirmed death from a cardiovascular cause. The secondary end points included the individual components of the primary end point and allcause mortality.

Although planned as a 5-year study, when patients in the rosuvastatin group had significantly fewer events and deaths than the controls, an independent data and safety monitoring board performed an interim efficacy analysis, and the trial was stopped after a median follow-up time of 1.9 years. About $75 \%$ of the treated participants were still taking rosuvastatin when the trial was ended. At that time there were 142 first major cardiovascular events in the rosu-

Table 2 Baseline clinical data in the JUPITER trial

\begin{tabular}{|c|c|c|}
\hline Characteristic & Treated group & Placebo group \\
\hline Age, years (\%) & 66 (median) & 66 \\
\hline Female sex, number (\%) & $3426(38.5)$ & $3375(37.9)$ \\
\hline \multicolumn{3}{|l|}{ Ethnicity } \\
\hline White, number (\%) & $6358(71.4)$ & $6325(71.1)$ \\
\hline Black, number (\%) & $1100(12.4)$ & II $24(12.6)$ \\
\hline Hispanic, number (\%) & $|12|(12.6)$ & $1140(12.8)$ \\
\hline Body mass index, $\mathrm{kg} / \mathrm{m}^{2}$ & 28.3 (median) & 28.4 \\
\hline Family history, number (\%) & $997(11.2)$ & $1048(11.8)$ \\
\hline Tobacco use number (\%) & $1400(\mid 5.7)$ & $1420(16.0)$ \\
\hline Systolic blood & I 34 (median) & 134 \\
\hline \multicolumn{3}{|l|}{ pressure, $\mathrm{mm} \mathrm{Hg}$} \\
\hline Diastolic blood & 80 & 80 \\
\hline \multicolumn{3}{|l|}{ pressure, $\mathrm{mm} \mathrm{Hg}$} \\
\hline \multicolumn{3}{|l|}{ CRP } \\
\hline $\mathrm{mg} / \mathrm{L}$ & $4.2(2.8-7.1)^{\mathrm{a}}$ & $4.3(2.8-7.2)$ \\
\hline $\mathrm{nmol} / \mathrm{L}$ & 40.0 (median) & 40.9 \\
\hline \multicolumn{3}{|l|}{ Triglycerides } \\
\hline $\mathrm{mg} / \mathrm{dL}$ & II8 (median) & 118 \\
\hline $\mathrm{mmol} / \mathrm{L}$ & 1.33 & 1.33 \\
\hline \multicolumn{3}{|l|}{ Total cholesterol } \\
\hline $\mathrm{mg} / \mathrm{dL}$ & 186 & 185 \\
\hline $\mathrm{mmol} / \mathrm{L}$ & 4.82 & 4.79 \\
\hline \multicolumn{3}{|l|}{ LDL cholesterol } \\
\hline $\mathrm{mg} / \mathrm{dL}$ & 108 & 108 \\
\hline $\mathrm{mmol} / \mathrm{L}$ & 2.8 & 2.8 \\
\hline \multicolumn{3}{|l|}{ HDL cholesterol } \\
\hline $\mathrm{mg} / \mathrm{dL}$ & 49 & 49 \\
\hline $\mathrm{mol} / \mathrm{L}$ & 1.27 & 1.27 \\
\hline \multicolumn{3}{|l|}{ Glucose } \\
\hline $\mathrm{mg} / \mathrm{dL}$ & 94 & 94 \\
\hline $\mathrm{mol} / \mathrm{L}$ & 5.22 & 5.22 \\
\hline $\mathrm{HbA}_{1 \mathrm{c}} \%$ & $5.7(5.4-5.9)$ & $5.7(5.5-5.9)$ \\
\hline Metabolic syndrome $(\%)^{b}$ & $3652(41.0)$ & $3723(41.8)$ \\
\hline
\end{tabular}

Notes: anterquartile range; 'Metabolic syndrome was defined according to the National Heart, Lung, and Blood Institute definition or American Heart Association consensus criteria.

Abbreviations: $\mathrm{HbA}_{\mathrm{Ic}}$, glycated hemoglobin; LDL, low-density lipoprotein. 
vastatin group, and 251 events in the placebo group, for a $44 \%$ reduction in first major cardiovascular events (HR 0.56 , 95\% confidence interval [CI] 0.46 to $0.69 ; P<0.00001$ ). There was also a $54 \%$ drop in nonfatal MI, a $48 \%$ reduction in nonfatal stroke, and a $47 \%$ fall in the cumulative incidence of hard end points of MI, stroke, or cardiovascular death in the rosuvastatin group (Table 3 ). In addition, there was a significant reduction in all-cause mortality of $20 \%$ in the treatment group, comparatively greater than in previous statin trials considering the duration. Rosuvastatin lowered CRP levels by $37 \%$, with a 12 month mean of $2.2 \mathrm{mg} / \mathrm{L}$, and lowered LDL by $50 \%$, with a mean treated value of $55 \mathrm{mg} / \mathrm{dL}$. Without a control group with normal CRP levels, whether CRP reduction was responsible for the observed benefits could not be answered.

The number needed to treat to prevent a first major primary end point event in 2 years was 95 , falling to 31 in 4 years, and 25 for 5 years of treatment with rosuvastatin. The cardiovascular event rate in the rosuvastatin group was about 1 in 100, compared to approximately 2 in 100 in the placebo group, an absolute risk reduction of $\approx 1.2 \%$ for the 1.9-month study. Hence 25 individuals would require treatment for 5 years to prevent a single event, an absolute risk reduction of about $4 \%$. Note that in primary prevention the baseline risk and event rate is low, so there is relatively less benefit in absolute risk anticipated. It is also instructive to compare the improvement in absolute risk achieved using the Mediterranean diet as the intervention, which may exceed $5 \%$ in some situations. ${ }^{304,305}$

JUPITER recorded 270 new cases of diabetes in the treatment group compared to 216 in the control group, and a rise in median glycated hemoglobin $\left(\mathrm{HbA}_{1 \mathrm{c}}\right)$ levels, also noted in prior statin studies, amounting to a $25 \%$ increase in physician-reported incidence of diabetes over a 1.9-year period. There were 10 cases of myopathy in the rosuvastatin group versus 9 in the control group, with only 1 instance of rhabdomyolysis associated with rosuvastatin, numbers that are consistent with previous rosuvastatin trials.

Given prior data that CRP values improved prediction of risk, JUPITER suggested that a seemingly healthy patient population at high risk, previously ineligible for statin therapy, may benefit from rosuvastatin treatment, guided by the CRP level. ${ }^{306}$ Attention was focused on the large body of research that points to inflammation as a common denominator in atherothrombosis, ie, that inflammation matters at a clinical level. ${ }^{57}$ JUPITER, called a landmark study immediately after presentation, has since been the subject of many editorials, discussions, and intense debate. An online poll conducted by the New England Journal of Medicine followed publication, with 2553 votes cast over 18 days. ${ }^{307}$ Half of the respondents believed JUPITER data should change screening in the general population, with the remainder voting against any change. Similarly, the votes for and against a change in the therapeutic use of statins based upon JUPITER results were about evenly divided.

\section{Subsequent analyses pertaining to JUPITER}

Using data from 1999-2004 NHANES and applying NCEP ATP III 2004 Update (ATP III) criteria, Spatz et al ${ }^{308}$ calculated that $57.9 \%$ of older adults (men $\geq 60$ years, women $\geq 50$ years) are either taking a statin $(24.4 \%)$ or eligible for a statin (33.5\%). If one includes individuals satisfying strict JUPITER criteria - no history of cardiovascular disease, $\mathrm{LDL}<130 \mathrm{mg} / \mathrm{dL}$, and CRP $\geq 2 \mathrm{mg} / \mathrm{L}-$ an additional $13.9 \%$ of the age group mentioned above, or nearly 8 million people,

Table 3 JUPITER trial: comparison of outcomes between treated and nontreated patients

\begin{tabular}{|c|c|c|c|}
\hline End point & $\begin{array}{l}\text { Patients in subgroup } \\
\text { rosuvastatin }(\mathrm{n}=890 \mathrm{I})\end{array}$ & $\begin{array}{l}\text { Patients in subgroup } \\
\text { placebo }(\mathrm{n}=890 \mathrm{I})\end{array}$ & Hazard ratio $(95 \% \mathrm{Cl})$ \\
\hline Primary end point ${ }^{\mathrm{a}}$ & 142 & 251 & $0.56(0.46-0.69)$ \\
\hline Any MI & 31 & 68 & $0.46(0.30-0.70)$ \\
\hline Nonfatal MI & 22 & 62 & $0.35(0.22-0.58)$ \\
\hline Any stroke & 33 & 64 & $0.52(0.34-0.79)$ \\
\hline Nonfatal stroke & 30 & 58 & $0.52(0.33-0.80)$ \\
\hline Revascularization & 71 & $|3|$ & $0.54(0.4 \mathrm{I}-0.72)$ \\
\hline Hospitalization for unstable angina & 16 & 27 & $0.59(0.32-1.10)$ \\
\hline $\begin{array}{l}\text { Revascularization or hospitalization } \\
\text { for unstable angina }\end{array}$ & 76 & 143 & $0.53(0.40-0.70)$ \\
\hline $\begin{array}{l}\text { MI, stroke, or death from } \\
\text { cardiovascular causes }\end{array}$ & 83 & 157 & $0.53(0.40-0.69)$ \\
\hline Any death & 198 & 247 & $0.80(0.67-0.97)$ \\
\hline
\end{tabular}

Notes: aPrimary end point: composite of nonfatal Ml, nonfatal stroke, hospitalization for unstable angina, revascularization, and death from cardiovascular causes. Abbreviations: $\mathrm{Cl}$, confidence interval; $\mathrm{MI}$, myocardial infarction. 
would become eligible for rosuvastatin therapy. If expanded JUPITER criteria were used - LDL between 130 and $160 \mathrm{mg} / \mathrm{dL}$ and CRP $\geq 2 \mathrm{mg} / \mathrm{L}$ - another $5.3 \%$, or 3 million individuals, would become statin-eligible. Hence a grand total of just under $80 \%$ of the older population would have an indication for statin therapy. Compared to the remaining $20 \%$, the "JUPITER group" was composed of more females, was older with a higher body mass index, and tended to have hypertension and metabolic syndrome. They also shared many characteristics with ATP III subjects, particularly the use of tobacco, visceral obesity, and hypertension. Interestingly, the investigators ${ }^{308}$ noted that in the Women's Health Study, about $20 \%$ of the women with low and intermediate FRS were reclassified by using the Reynolds risk score, which incorporates CRP values. ${ }^{35,256,263}$ These findings support the growing realization that risk is greater than generally believed, and the validity of CRP-guided risk reduction.

Michos and Blumenthal ${ }^{309}$ also estimated the prevalence of JUPITER-eligible individuals in the US population using NHANES 1999-2004 data. They found about 6.5 million individuals would be added if strict JUPITER criteria were followed. Based upon the number needed to treat (NNT) of 25 at 5 years, they estimated about 260,000 cardiovascular events could be prevented with rosuvastatin therapy. A subsequent recalculation, after adding the number of venous thromboses that would be avoided, raised the number to about 500,000 per annum.

Ridker ${ }^{310}$ clarified aspects of the JUPITER study in mid2009, observing that all prespecified subgroups benefited by rosuvastatin therapy, including those participants considered at low risk. The decision to terminate the study early was based on rigorous pre-agreed principles. It was noted that the NNT to prevent 1 event for 5 years was comparable to that reported in AFCAPS/TexCAPS, and less than those accepted for the use of diuretics or beta-blockers in treating hypertension for primary prevention. Another point emphasized was that $80 \%$ of individuals who developed diabetes occurred among those participants who had impaired glucose tolerance at baseline, but those patients also benefited from treatment in terms of end points. Last, reduction of both LDL and CRP levels was especially successful, and dual targeting may simplify decisions to treat. Another detailed analysis of absolute risk reductions and consequent NNT within the JUPITER trial, including alternative statin regimens, concluded that NNT values are acceptable. ${ }^{311}$

Yang et al, ${ }^{312}$ using a JUPITER-eligible cohort from the Atherosclerosis Risk in Communities (ARIC) Study (men $\geq 50$, women $\geq 60, \mathrm{CRP} \geq 2 \mathrm{mg} / \mathrm{L}, \mathrm{LDL}<130 \mathrm{mg} / \mathrm{dL}$ ), sought to determine if the absolute event rates and risk reduction seen in JUPITER would persist for a period longer than the 1.9 year follow-up. Of their JUPITER-eligible participants, there was an absolute CVD risk of $\approx 10.9 \%$ over a mean follow-up of 6.9 years, or $1.57 \%$ per year. Applying JUPITER HRs to this group generated an NNT of 38 over 5 years and 26 over 6.9 years. They concluded that the use of age and CRP level was a convenient method of identifying higher risk individuals.

Vaccarino and coworkers ${ }^{313}$ noted the absolute risk reduction of $0.59 \%$ per year for the primary end point required 169 persons to be treated for 1 year to prevent a single combination of events. To prevent a major coronary event, such as an MI, 500 patients needed to be treated for 1 year for a single event. An estimate of a drug cost for rosuvastatin of US\$638,750 per year was made to prevent 1 event, and for a generic statin, US\$24,000 per year. In their view, adding CRP screening costs of US\$62,500, and then for additional liver function, glucose, and $\mathrm{HbA}_{1 \mathrm{c}}$ monitoring, a total of over US\$137,000 was reached per year for each event prevented. These authors suggested that the funds instead be invested in effective, proven population-based strategies to lower risk, as discussed elsewhere. ${ }^{314-316}$ In general, the costs per life year for lifetime treatment using simvastatin vary from US\$2500 to US\$10,990, depending on age and risk. ${ }^{317}$ Accad and Fred ${ }^{318}$ also opined that, according to their calculations, treatment of 95 individuals for 2 years to avoid 1 event is not a sufficient reward for the person with a high CRP level, but may be acceptable on a population level. On the other hand, Slejko et $\mathrm{al}^{269}$ maintained that statin therapy in JUPITER patients is cost-effective, at a cost of US\$40,457 per quality adjusted life-year, below the customary threshold of US\$50,000. MacDonald ${ }^{271}$ estimated that treating JUPITEReligible individuals with rosuvastatin is highly cost-effective, but is a function of the initial FRS.

Kappagoda and Amsterdam ${ }^{319}$ reviewed treatment in the JUPITER study according to traditional risk factors and guidelines, and their calculations showed the following. Baseline characteristics of the participants revealed 2225 in each group with systolic blood pressures over $145 \mathrm{~mm} \mathrm{Hg}$. Treating these elevations would have lowered the number of strokes by 12 over the duration of the study. Similarly, by treating those individuals with LDL $>119 \mathrm{mg} / \mathrm{dL}$ and HDL $<40 \mathrm{mg} / \mathrm{dL}$ (about $25 \%$ of the subjects), and overweight individuals ( $>50 \%$ ) with weight loss, and eliminating tobacco use in the $16 \%$ who smoked, along with administering evidence-based aspirin prophylaxis in men for CHD prevention, and in women for stroke prevention, meaningful 
benefits would have changed outcomes. Aspirin alone could potentially have prevented 72 of the 99 MIs that occurred during the course of the JUPITER trial. Finally, since the baseline median $\mathrm{HbA}_{1 \mathrm{c}}$ was $5.7 \%$ (reference range $4.8 \%$ to $5.9 \%$ ), 2225 individuals in each group had levels $>5.9 \%$, suggesting that close to $25 \%$ of the entire JUPITER population met this criterion for diabetes. These authors suggested that because guidelines for care were not strictly followed, a spuriously high event rate may have caused an appearance of higher benefit from statin therapy. The event rate, however, was similar in the ARIC profile cohort that was JUPITER-eligible, ${ }^{312}$ although smaller, which would argue against this view.

A most significant dual target analysis of the JUPITER study evaluated the effects of rosuvastatin $20 \mathrm{mg}$ versus placebo on the prespecified end points according to on-treatment values of $\mathrm{LDL}(<70$ or $\geq 70 \mathrm{mg} / \mathrm{dL})$ and CRP $(<2 \mathrm{mg} / \mathrm{L}$, or $<1 \mathrm{mg} / \mathrm{L}$ ). ${ }^{320}$ Compared to placebo, those in the treatment group who achieved an LDL $<70 \mathrm{mg} / \mathrm{dL}$ had a $55 \%$ reduction in vascular events per 100-person years (Table 4). Those who achieved CRP $<2 \mathrm{mg} / \mathrm{L}$ had a $62 \%$ reduction in events. Among those who reached dual reductions, there was a $65 \%$ reduction in events compared to a $33 \%$ reduction in those who achieved one or neither target. Those who reached an $\mathrm{LDL}<70 \mathrm{mg} / \mathrm{dL}$ and a $\mathrm{CRP}<1 \mathrm{mg} / \mathrm{L}$ enjoyed a 79\% reduction in events (Table 5). Treatment CRP levels predicted the event rate no matter what lipid end point was used, including the ratio of aopB/aopA-1. Therefore, regardless of the lipid profile, the lower the CRP, the better was the prognosis. An editorial concluded that JUPITER provided "key experimental data" that inflammation mediated the benefits of rosuvastatin, but mused at the prospect of comparing the absolute risk reduction of statins with the effects of weight loss and regular exercise, remarking that such a study is unlikely, ${ }^{321}$ both for lack of funding and interest. Many of the pleiotropic effects of rosuvastatin are anti-inflammatory, and a catalog of those actions - significant improvement in endothelial function, immune responses, plaque stabilization, vascular remodeling, and oxidative stress - and antithrombotic actions ${ }^{322}$ further underpins the observation that targeting CRP is worthwhile and clinically rewarding.

The use of statins in women, particularly for primary prevention, has been heavily debated. ${ }^{323-325}$ Mora and cowork$\mathrm{ers}^{326}$ performed a specific gender-specific analysis from JUPITER using rosuvastatin $20 \mathrm{mg}$ or placebo employing the criteria mentioned above. Focusing only on 6801 female participants in JUPITER, treatment significantly lowered the relative risk of the primary end point, composite of MI,
Table 4 Cardiovascular events fell based on LDL cholesterol and on hs-CRP levels $<2 \mathrm{mg} / \mathrm{L}$

\begin{tabular}{lll}
\hline $\begin{array}{l}\text { LDL cholesterol }(\mathrm{mg} / \mathrm{dL}) \\
\text { and } \mathbf{h s}-\mathbf{C R P}(\mathbf{m g} / \mathbf{L}) \text { values }\end{array}$ & Event rate & $\begin{array}{l}\text { Hazard ratio } \\
\mathbf{9 5 \%} \mathbf{C l})\end{array}$ \\
\hline$\geq 70$ and $\geq 2$ & $\mathrm{I} .1 \mathrm{I}$ & $\mathrm{I} .06(0.72-1.55)$ \\
$\geq 70$ and $<2$ & 0.54 & $0.42(0.18-0.94)$ \\
$<70$ and $\geq 2$ & 0.62 & $0.53(0.38-0.74)$ \\
$<70$ and $<2$ & 0.38 & $0.35(0.23-0.54)$ \\
$\geq 70$ or $\geq 2$ & 0.38 & $0.64(0.49-0.84)$ \\
\hline
\end{tabular}

Abbreviations: $\mathrm{Cl}$, confidence interval; LDL, low-density lipoprotein; hs-CRP, high CRP.

Table 5 Cardiovascular events fell based on LDL cholesterol and on hs-CRP levels $<$ I mg/L

\begin{tabular}{lll}
\hline $\begin{array}{l}\text { LDL cholesterol }(\mathrm{mg} / \mathrm{dL}) \\
\text { and } \mathbf{h s}-\mathrm{CRP}(\mathbf{m g} / \mathbf{L}) \text { values }\end{array}$ & Event rate & $\begin{array}{l}\text { Hazard ratio } \\
\mathbf{( 9 5 \% ~ C l )}\end{array}$ \\
\hline$\geq 70$ and $\geq I$ & 0.95 & $0.89(0.62-1.28)$ \\
$\geq 70$ and $<1$ & 0.64 & $0.46(0.1 \mathrm{I}-1.85)$ \\
$<70$ and $\geq 1$ & 0.56 & $0.49(0.37-0.66)$ \\
$<70$ and $<1$ & 0.24 & $0.21(0.09-0.51)$ \\
$\geq 70$ or $\geq 1$ & 0.67 & $0.59(0.46-0.75)$
\end{tabular}

Abbreviations: $\mathrm{Cl}$, confidence interval; LDL, low-density lipoprotein; hs-CRP, high CRP.

stroke, revascularization, hospitalization for unstable angina, and death from cardiovascular causes, by $46 \%$. The greatest benefit was seen for revascularization, associated with a treatment-related reduction of $76 \%$ compared to placebo. A meta-analysis of 5 studies reporting sex-specific outcomes was also undertaken. Absolute CVD rates per 100 person-years in JUPITER women were lower than for men, with similar relative risk reductions between the sexes. A total of 13,154 women were included from primary prevention trials, and a significant reduction in primary CVD events with statins by one-third was found (relative risk $0.63 ; 95 \%$ CI 0.49 to 0.82 ; $P<0.001)$. These results were similar to prior results in men, and also to findings for secondary prevention in women. It was postulated that the greater numbers enrolled allowed JUPITER to demonstrate the benefit. ${ }^{327} \mathrm{CRP}$ was noted as a tighter predictor of events in women than in men, along with the correlation between the degrees of CRP lowering and associated clinical benefit. These authors concluded that while CRP level as an independent predictor of events remains controversial, CRP is accepted as a marker which may be involved in the atherogenic process. ${ }^{237}$

The FDA approved rosuvastatin for primary prevention on February 9, 2010, following a 12-4 vote in a panel 2 months before, which only seemed to flare the ongoing controversy about its use in "healthy" individuals. ${ }^{328}$ The new indication was for men $\geq 50$ years and women $\geq 60$ years with fasting LDL 
$\leq 130 \mathrm{mg} / \mathrm{dL}, \mathrm{CRP} \geq 2.0 \mathrm{mg} / \mathrm{L}$, triglycerides $\leq 500 \mathrm{mg} / \mathrm{dL}$, no diagnosed CVD, and at least 1 additional CVD risk factor.

\section{Summary of articles in the Archives of Internal Medicine}

Kaul and collaborators ${ }^{329}$ challenged 3 aspects of the JUPITER study, asking (a) does CRP predict risk and treatment response? (b) did early stoppage of JUPITER unduly raise the benefit? and (c) what about guideline recommendations? First, they believed that the predictive value of $1.35 \%$, although positive in JUPITER (241 events in 17,802 patients), was weak, and basically that treatment decisions should not be stratified using CRP values because there was no low-CRP, low-LDL control arm for comparison. This arm was excluded in the design of JUPITER because of the prior post-hoc analysis of AFCAPS/TexCAPS showing no benefit in a group with low CRP. ${ }^{246,330}$ The JUPITER authors hypothesized, with considerable supporting evidence from other investigators and studies outlined above, that high CRP levels reflected increased risk, and treatment with rosuvastatin addressed that component over and above any LDL lowering. ${ }^{310} \mathrm{~A}$ fair consensus from the many commentaries and blogs would be that a high level of CRP does have clinical utility, portends an otherwise poorer prognosis, but a normal CRP value does not assure low risk.

Second, the early termination of JUPITER may have led to a somewhat higher benefit than would have been observed from a longer study period. Compared to other statin studies in primary prevention, JUPITER reported unexpectedly larger reductions in ischemic end points including mortality. Studies terminated prematurely in other trials are known to exaggerate benefits, which regresses to the mean when follow-up is longer. ${ }^{331-334} \mathrm{~A}$ large systematic review reported that for interventions showing a $20 \%$ improvement in completed trials, stopping them early might double the apparent benefit. ${ }^{332}$ It is true that other studies used less potent statins, but a rapid mortality benefit within this period is exceptional. Details provided subsequent to JUPITER concerning the circumstances of the early termination did not reflect any intent to exaggerate the positive results. Kaul agreed that rosuvastatin benefits did occur in JUPITER, although perhaps were increased by the early stoppage of the study. ${ }^{330}$ The pathology in the CORONA and AURORA populations was sufficiently different from JUPITER to make a comparison of results difficult.

Third, Kaul et al ${ }^{329}$ question the conclusion that high CRP levels predict preferential improved response in JUPITER, based on an FDA analysis showing, essentially, that treatment effect of statins was not proportional to the degree of elevation in CRP. ${ }^{335}$ This conclusion was based on a stratification of FRS risk scores according to the CRP level. In addition, however, data presented in Tables 4 and 5 show a clear relationship between low CRP values and good prognosis. ${ }^{321}$ Kaul et al concluded that $44 \%$ risk reductions in JUPITER-eligible patients in the population will not be typically attained if CRPguided rosuvastatin therapy is used. Their second conclusion, with which everyone agrees, is that control of risk factors with lifestyle modification trumps pharmacologic intervention in primary prevention. The third conclusion advises that if patients do not change their lifestyle, then statins may be used. In practice, since $\approx 95 \%$ of individuals will fall into this category, ultimately most patients will receive statins, simply because there are no comparable alternatives.

De Lorgeril et $\mathrm{a}^{336,337}$ maintained that a) there was a discrepancy between the reduction in mortality between end point subgroups; b) cardiovascular mortality was $5 \%$ to $18 \%$ compared with total mortality and the expected rate is about $40 \%$; c) the case-fatality rate of MI was low compared to an expected figure of $50 \%$; the case mortality rate in the placebo group was $8.8 \%$ compared to $29 \%$ in the rosuvastatin group; d) no sudden cardiac death was reported in JUPITER; and e) bias may have been introduced because of conflicts of interest and commercial sponsorship. These analysts believed that there was no significant difference in cardiovascular mortality between the two groups in JUPITER. Last, they lamented the secondary end point and subgroup analyses published concerning benefit in preventing venous thromboembolic disease, ${ }^{338}$ efficacy in women, ${ }^{326}$ lower stages of chronic renal disease, ${ }^{339}$ and in the elderly ${ }^{340}$ because they shared the limitations of the original study.

Several of the earnest concerns summarized in the papers by $\mathrm{Kaul}^{329}$ and de Lorgeri1 ${ }^{336}$ have been addressed by investigators other than JUPITER, and have also been answered in part by subanalyses and refinements presented by the JUPITER authors during the past 2 years. For instance, the association of high levels of CRP with vascular risk has considerable supportive evidence from multiple sources, and the recent meta-analysis of 54 prospective studies by the Emerging Risk Factors Collaboration confirmed this relationship. ${ }^{237}$ Specifically, the adjusted risk associated with a 1-standard deviation increase in CRP (HR 1.4; 95\% CI 1.3 to 1.5 ) compared quite favorably with that associated with a similar increase in cholesterol (HR 1.2; 95\% CI 1.1 to 1.3 ).

A closer evaluation of the relationship between baseline CRP measurements and cardiovascular risk is also available. ${ }^{268}$ Treating CRP as a continuous variable, an 
ordinal variable and as a threshold variable, relative risk reduction after rosuvastatin therapy was similar maintained across the entry levels of CRP. Absolute risk reductions therefore were greatest in the patients with the highest entry levels of CRP. Independent corroboration of these data is found in the ARIC study ${ }^{312}$ in which groups with similar FRS and LDL levels had higher vascular risk when the CRP was elevated, compared to counterparts with low CRP values.

\section{JUPITER findings incorporated into the Canadian Cardiovascular Society guidelines}

The Canadian Cardiovascular Society acknowledged JUPITER findings in their guidelines and recommended measurement of CRP in JUPITER-eligible individuals at "intermediate risk" as a step toward prophylactic statin treatment. ${ }^{257}$ The Society extended recommendations from the CDC in which CRP levels were considered an adjunct to risk assessment in healthy persons with an FRS between 5\%-20\%, ie, at intermediate risk. ${ }^{341}$ In JUPITER, the event rate in the placebo group was greater than in AFCAPS/ TexCAPS study, and most individuals had an FRS between $5 \%$ and $20 \%$. Analysis of JUPITER trial data stratified according to both the Framingham and Reynolds 10-year risk scores confirmed that treatment of JUPITER-eligible men and women in the "intermediate" categories (5\% to $10 \%$ and $10 \%$ to $20 \% 10$-year risk) significantly reduced cardiovascular events. ${ }^{342}$ In the $5 \%$ to $10 \%$ FRS category who were treated, HR was 0.55 (95\% CI 0.36 to 0.84 ;
5 -year NNT $=40, P=0.005$ ) (Table 6 ). In the $11 \%$ to $20 \%$ risk category, HR was 0.51 (95\% CI 0.39 to $0.68,5$-year $\mathrm{NNT}=18 ; P<0.0001)$.

Using the FRS, no significant benefit occurred in the groups with either low or very high risk. The Reynolds risk score reclassified more individuals into these two categories, low $(<5 \%)$ and high $(>20 \%)$, and rosuvastatin did produce a benefit in those at highest risk. Since the FRS underestimates risk in women, and frequently women do not have FRS $>10 \%$, they may not be considered for treatment under current guidelines. Using CRP $\geq 2 \mathrm{mg} / \mathrm{L}$ as part of JUPITER criteria would include almost 7000 of such women who could potentially benefit from rosuvastatin therapy. This number becomes considerable in view of the growing awareness of serious gender disparities in CHD treatment. ${ }^{343}$

\section{Summary of response of JUPITER authors}

Ridker and Glynn ${ }^{330,344}$ and Ridker ${ }^{345}$ responded to the four major issues raised by De Lorgeril et al, ${ }^{336}$ namely a potential deficiency in trial design and execution; early termination of the study was inappropriate and/or favored to exaggerate benefit; inconsistencies existed concerning mortality, statin treatment and CRP; and pharmaceutical company sponsorship played a significant part in the positive outcomes, as summarized below.

\section{JUPITER study design}

The study was logically designed, participant follow-up was careful and full, end point adjudication was rigorous, and followed a pre-specified analysis plan.

Table 6 Event rates and hazard ratios for the primary end point correlated with estimated I0-year Framingham and Reynolds risk scores at baseline

\begin{tabular}{|c|c|c|c|}
\hline Risk level & $\begin{array}{l}\text { Event rate/ } 100 \text {-person years, } \\
\text { rosuvastatin } 20 \mathrm{mg} \text { group }\end{array}$ & $\begin{array}{l}\text { Event rate/ I 00-person years, } \\
\text { placebo group }\end{array}$ & Hazard ratio $(95 \% \mathrm{Cl})$ \\
\hline \multicolumn{4}{|l|}{ Framingham I0-year risk score } \\
\hline$<5 \%(n=2791,173$ men, 2618 women $)$ & 0.22 & 0.34 & $0.64(0.23-1.8 I)$ \\
\hline \multirow{2}{*}{$5 \%-10 \%(n=6091,2525$ women, 3566 men $)$} & 0.50 & 0.92 & $0.55(0.36-0.84)$ \\
\hline & & & 5 -year NNT $=40^{\mathrm{a}}$ \\
\hline \multirow[t]{2}{*}{ II\%-20\% ( $\mathrm{n}=7340,1404$ women, 5936 men $)$} & 0.95 & 1.84 & $0.5 I(0.39-0.68)$ \\
\hline & & & 5 -year NNT $=18^{b}$ \\
\hline$>20 \%(n=\mid 555,242$ women, 1313 men $)$ & 1.72 & 2.41 & $0.70(0.43-1.14)$ \\
\hline \multicolumn{4}{|l|}{ Reynolds I0-year risk score } \\
\hline$<5 \%(n=3583,944$ men, 2639 women $)$ & 0.26 & 0.41 & $0.62(0.27-1.43)$ \\
\hline $5 \%-10 \%(n=6436,265 I$ women, 3785 men $)$ & 0.44 & 1.00 & $0.45(0.29-0.68)$ \\
\hline $11 \%-20 \%(n=5040,1151$ women, 3889 men $)$ & 1.07 & 1.65 & $0.65(0.47-0.90)$ \\
\hline$>20 \%(n=265 \mathrm{I}, 327$ women, 2324 men $)$ & 1.55 & 2.84 & $0.55(0.38-0.80)$ \\
\hline
\end{tabular}

Notes: ${ }^{a}$ Corresponds to estimated absolute risk difference between treated and placebo groups at 5 year of $\approx 2.5$ events/100 person-years; ${ }^{b}$ Corresponds to estimated absolute risk difference between treated and placebo groups at 5 year of $\approx 5.7$ events/ 100 person-years.

Abbreviations: $\mathrm{Cl}$, confidence interval; NNT, number needed to treat. 


\section{Early termination of the trial}

The details concerning the charter between the investigators and members of the independent Monitoring Board that decided to end the trial early were described. The decision to do so followed that agreement and was just and proper. The investigators reiterated that any overestimate of relative risk reduction involved would have been small, estimated by an FDA statistical analysis at $\leq 1 \%$. ${ }^{346}$ Since the benefit was highly significant at $44 \%$ reduction in relative risk for the primary end point, there would be no clinically significant change in outcome interpretation. Simulation studies indicated that stopping the study early under similar circumstances produced valid treatment results. ${ }^{347,348}$

The benefits of rosuvastatin therapy in JUPITER were much larger than those reported in earlier statin trials. However, the relative risk lowering in JUPITER was similar to the analysis of a JUPITER-eligible cohort in the AFCAPS/ TexCAPS study previously reported. ${ }^{246}$ In addition, earlier statin trials showed that a $1 \%$ fall in LDL level corresponded to a $1 \%$ reduction in relative risk. This was approximately the same in JUPITER, since rosuvastatin lowered LDL by $50 \%$, and the resulting fall in relative risk was about the same magnitude.

A sequential review of the benefit of rosuvastatin treatment throughout JUPITER demonstrates that the differences between treatment and placebo groups increased steadily as the study progressed, rather than decreased. ${ }^{344}$

\section{Inconsistencies in case-fatality rate}

Instances of events and deaths required proof to be classified as cardiovascular, and many out-of-hospital deaths were termed "noncardiovascular" in the absence of such proof. There were 35 deaths from CVD in the treated group and 43 in the placebo group. The death rates for SCD were
16 in the rosuvastatin group versus 25 in the placebo group, suggesting a larger beneficial effect in the SCD component than was reported for total and cardiovascular mortality (Table 7).

\section{Influence of the sponsor-affected outcomes}

The sponsor, AstraZeneca, had no access to the data or any role in the analyses or manuscript writing.

\section{Side effects}

Pharmaceuticals nearly always have side effects, but most do not rise to clinical significance. Adverse events associated with statins have been exceptionally well studied. As the most potent member of its class, rosuvastatin is also associated with unwanted events. Molecular mechanisms have yet to be fully characterized. No one study imposes use of drugs on any patient - use is weighed on the ratio of potential benefits with respect to risks, first by the FDA, then subsequently by the prescribing physician. A vast amount of clinical evidence suggests that, for statins in general, and rosuvastatin in particular, this ratio is large.

JUPITER reported a rise in the number of cases of diabetes in the treatment group, amounting to 270 events, or about a $25 \%$ increased risk of developing diabetes. In about $1.4 \%$ of prescriptions, rosuvastatin has to be discontinued due to adverse reactions, with the Package Insert quoting the incidence of myalgia at 3.1\%, abdominal discomfort, $2.6 \%$, asthenia, $2.5 \%$, and nausea at $2.2 \%$. The frequency of overt myotoxicity, with diagnostic elevations in creatine kinase (CK) 10-fold higher than the upper limit of normal and requiring inpatient care, is in the order of 0.4 per 10,000 person-years. ${ }^{349,350}$ Less severe myalgia, however, may be responsible for discontinuing statins in $5 \%$ to $10 \%$ of statin users. ${ }^{351,352}$ Both myotoxicity and an increase in the incidence

Table 7 Components of the primary end point reached in the JUPITER study

\begin{tabular}{|c|c|c|c|c|c|}
\hline End point & Rosuvastatin group & Placebo group & Hazard ratio & $95 \% \mathrm{Cl}$ & $P$ value \\
\hline Primary end point & 142 & 251 & 0.56 & $0.46-0.69$ & $<0.00001$ \\
\hline Nonfatal MI & 22 & 62 & 0.35 & $0.22-0.58$ & $<0.00001$ \\
\hline Any MI & 31 & 68 & 0.46 & $0.30-0.70$ & $<0.0002$ \\
\hline Nonfatal stroke & 30 & 58 & 0.52 & $0.33-0.80$ & 0.003 \\
\hline Any stroke & 33 & 64 & 0.52 & $0.34-0.79$ & 0.002 \\
\hline Revascularization or & 76 & 143 & 0.53 & $0.40-0.70$ & $<0.00001$ \\
\hline \multicolumn{6}{|l|}{ Unstable angina } \\
\hline MI, stroke, CV death & 83 & 157 & 0.53 & $0.40-0.69$ & $<0.00001$ \\
\hline Total mortality & 198 & 247 & 0.80 & $0.67-0.97$ & 0.02 \\
\hline CV death (verified) & 35 & 43 & 0.82 & $0.52-1.27$ & 0.37 \\
\hline Sudden death & 16 & 25 & 0.64 & $0.34-1.20$ & 0.16 \\
\hline
\end{tabular}

Abbreviations: $\mathrm{Cl}$, confidence interval; CV, cardiovascular; MI, myocardial infarction. 
of diabetes, as noted in JUPITER, are currently of greatest interest.

\section{Statins raise incidence of diabetes}

In a study of 345,417 men, Sukhija et $\mathrm{al}^{353}$ reported that a decrease in insulin sensitivity was a class effect of statin drugs, and found that the change in fasting plasma glucose level in nondiabetic statin users was $7 \mathrm{mg} / \mathrm{dL}$ (versus $5 \mathrm{mg} / \mathrm{dL}$ in patients not using statins; $P<0.0001$ ), and in diabetic statin users, the rise was $39 \mathrm{mg} / \mathrm{dL}$ (versus $32 \mathrm{mg} / \mathrm{dL}$ in patients not using statins; $P<0.0001)$. The effect has subsequently been confirmed for atorvastatin ${ }^{354}$ and for rosuvastatin, ${ }^{355}$ which produced a dose-dependent rise in insulin resistance. Using data from the Cholesterol Treatment Trialists' Collaborators, ${ }^{356}$ Sattar and colleagues ${ }^{357}$ conducted a meta-analysis of 13 randomized statin trials and studied the incidence of diabetes among 91,140 participants. Statin therapy was associated with a $9 \%$ increased risk for diabetes, translating to 1 extra case of diabetes per 255 patients treated over 4 years. Absolute risk was low, at 1 case per 1000 patient-years of treatment. During those 4 years, however, 5.4 MIs or cardiovascular deaths and 5.4 coronary revascularizations and strokes would be prevented, amounting to an overall benefit of 9:1 events. Their analysis also indicated that lowering glucose tolerance was a class effect of statins, in agreement with a review of several statin trials prior to JUPITER. ${ }^{310}$ Baker et $\mathrm{al}^{358}$ systematically reviewed 16 studies and determined there was no class effect of statins upon glucose tolerance in patients without diabetes, and that differences between statins may have accounted for prior findings.

Some side effects of statins are obligatory consequences of HMGR inhibition of the mevalonate pathway used for cholesterol synthesis (Figure 2), and are molecularly unavoidable, extending throughout the metabolome. Among the intermediate products of this pathway are the 15-carbon farnesyl pyrophosphate and 20-carbon geranylgeranyl pyrophosphate molecules, used to add an isoprenoid group to over 100 signaling proteins in a fundamental posttranslational modification known as prenylation. ${ }^{359}$ This addition of an isoprenoid group is necessary for function of small Rho-family GTPases such as Rac, Rho, and Rab. Some of these GTPases serve as molecular switches, and others are involved in intracellular membrane trafficking, using the lipophilic prenyl group to anchor in membranes. ${ }^{360}$ Many desirable pleiotropic actions of statins, such as the antioxidant, anti-inflammatory, and antiproliferative properties $^{361-363}$ may be related to decreased ability to prenylate signaling molecules. Inhibition of Rho and its downstream target Rho kinase (ROCK) function is especially important, since elevated ROCK activity may occur in association with elevated CRP levels ${ }^{364}$ and contribute to atherosclerosis. ${ }^{365,366}$ Less desirable consequences of HMGR inhibition may arise from deficiencies in downstream metabolites of the mevalonate pathway such as ubiquinone and dolichol, which are, respectively, ignored and largely unknown. Dolichol, a family of linear polyisoprenols containing 16 to 22 isoprene units, are carriers involved in N-glycosylation of nascent polypeptides, and serve as sites for assembly of oligosaccharides during the formation of glycoproteins, ensuring the membrane fluidity and permeability required for glycoprotein maturation and secretion.

There are several signaling steps between the insulin receptor and translocation of the glucose transporter GLUT4 from specialized intracellular compartments to the plasma membrane. Individual statins may have different effects upon these steps, and which of them predominate may account for differences on overall glucose tolerance. ${ }^{367}$ Thus, in one preparation, atorvastatin may improve glucose tolerance, possibly by lowering membrane cholesterol content $^{368}$ yet in another report atorvastatin appeared to attenuate the expression of GLUT-4 in adipocytes to lower glucose tolerance. ${ }^{369}$ In addition, there may be differential effects of statins upon levels of adiponectin, leptin, and other inflammatory mediators that affect glucose intolerance. Differences in lipophilicity among the statins may contribute both to the effects on insulin sensitivity and myotoxicity. Pravastatin, which improves glucose tolerance when compared with atorvastatin, has a relatively favorable effect on beta-cell function. ${ }^{370,371}$ It has been suggested that pravastatin, hydrophilic but forming weak steric interactions with HMGR, has limited ability to block the mevalonate pathway in cells outside the liver. ${ }^{358}$ Simvastatin, which worsens glucose tolerance, has a greater affinity for cell membranes due to its lipophilicity, and may block L-type calcium channels, interfering with glucoseinduced cytosolic calcium signaling and insulin secretion in beta cells. ${ }^{372}$ Another possible explanation for statininduced glucose intolerance includes dysfunctional insulin receptors and/or insulin-like growth factor receptors as a result of impaired glycosylation (see above). ${ }^{373}$ Finally, by upregulating hepatic LDL receptors, a greater number of triglyceride-rich particles returning to the liver may induce hepatic insulin resistance. ${ }^{374}$

In view of the large reduction in major vascular events associated with use of statins in diabetics, ${ }^{356}$ the small increase in diabetes discussed above has not changed clinical 
practice, ${ }^{375}$ and further work is needed to delineate its clinical significance.

\section{Statin-induced myopathy}

Statin myotoxicity is a major concern of practitioners; part of the reluctance to titrate LDL levels down to guideline targets is a fear of myopathy. Although this phenomenon has received enormous attention from researchers, clinicians, the lay press, and on the internet, its mechanism and optimal management remain uncertain. The spectrum of myopathy or myotoxicity includes myalgia (muscle ache or weakness without $\mathrm{CK}$ elevation), myositis (muscle symptoms with raised CK levels), and rhabdomyolysis (symptoms with $\mathrm{CK}$ over the upper limit of normal by a factor of at least 10). ${ }^{376}$ Myalgia is noted in randomized statin trials in the order of $<3 \%$, compared to the incidence in outpatient lipid clinics, which varies between $5 \%$ and $10 \% .{ }^{377}$ Underreporting is commonly assumed, but individuals with predisposing conditions are carefully screened, and many randomized trials include a run-in period, then fail to randomize candidates with myopathic symptoms.

During vigorous exercise, the phenomenon is accentuated, raising the reported incidence of myalgia up to $25 \%$. ${ }^{378}$ Statin intolerance among athletes is well known. Factors that predispose to myopathy are increasing age, female gender, hepatic or renal disease, diabetes, polypharmacy, and any condition that diminishes muscle reserve (small frame, frailty, sarcopenia), or causes muscle pathology, including hypothyroidism or hyperthyroidism, metabolic muscle disease, polymyalgia rheumatica, autoimmune diseases with myositis, postoperative status, hypovitaminosis D, chronic alcohol use, and others.

Some adverse reactions may be minimized by avoiding negative drug-drug interactions. As mentioned above, since rosuvastatin is not eliminated through the CYP3A4 pathway, only minimally metabolized by the CYP2C9 enzyme, and does not interfere with P-gp, drugs that inhibit OATP1B1, a transporter that facilitates rosuvastatin uptake in the liver, may clinically be more important offenders than cytochrome P450 inhibitors or substrates. Common drugs usually mentioned that may raise the likelihood of myotoxicity are cyclosporine, gemfibrozil, itraconazole, ketoconazole, fluconazole, lopinavir/rotinavir, atazanavir/ritonavir, fosamprenavir/ritonavir, warfarin, and amiodarone. Some of the quantitative effects of coadministered drugs are summarized in Tables 8 and 9. As noted in Table 9, digoxin coadministered with rosuvastatin only raises the AUC 4\%, reflecting the statin is not a P-gp substrate. Genetic polymorphism within $S L C O 1 B 1$, the gene that encodes OATP1B1, produces a variant which increases susceptibility to statin-induced myopathy. ${ }^{379}$

Since statins affect many different molecules and signaling systems, the mechanism of statin myopathy also remains uncertain. A relationship to a deficiency of prenylating moieties, farnesyl pyrophosphate and geranylgeranyl pyrophosphate, is again likely. Inability to prenylate selenoproteins, dolichols, and small GTPases Rho, Ras, and Rac is believed to disturb intracellular trafficking of proteins between membranes needed for muscle growth and repair. Statins specifically activate mechanisms that lead to muscle atrophy in a number of circumstances, mediated by overexpression of atrogin-1, a muscle-specific E3 ubiquitin ligase in the ubiquitin proteasome proteolytic pathway. ${ }^{380-382}$ Induction of atrogin-1 appears to be significant in the pathogenesis of statin myopathy, but is by no means the only mechanism. Experimental overexpression of peroxisome proliferatoractivated receptor-gamma coactivator- $1 \alpha$ (PPAR $\gamma$ coactivator $1 \alpha$ or $\mathrm{PGC}-1 \alpha$ ), coactivator of many transcription factors and a regulator of mitochondrial number and function, attenuates statin-induced atrogin-1 expression, protects against statin myotoxicity, and may lead to a therapeutic target.

Skeletal muscle expresses drug transporters such as OATP2B1, high-affinity uptake transporters for both atorvastatin and rosuvastatin. ${ }^{383}$ A number of efflux transporters, multidrug-resistance-associated proteins 1,4 , and 5, are also expressed on the sarcolemmal membrane of skeletal muscle. Susceptibility to myotoxicity may depend not only on the serum concentration of rosuvastatin, but also locally on the balance between activities of muscle fiber uptake and efflux transporters. For example, in one experimental model, probenecid, which inhibits efflux transporter MRP1, raised myocyte rosuvastatin levels and promoted myotoxicity. ${ }^{384}$

Lipophilic statins, such as lovastatin or simvastatin, inhibit protein synthesis in skeletal myotubules to a greater extent than hydrophilic statins, such as pravastatin. ${ }^{385}$ Statins in higher doses may decrease the ability of muscle progenitor cells (satellite cells) to repair and regenerate skeletal muscle. ${ }^{386}$ Only in part because they severely reduce ubiquinone (coenzyme Q10) levels, statins are associated with multiple defects in muscle mitochondrial anatomy and function. ${ }^{387}$ Lower mitochondrial volume, mitochondrial DNA loss, reduction in mitochondrial membrane potential, inefficient oxidative phosphorylation, anatomical fractionation, leakage of pro-apoptotic chemicals through mitochondrial membranes, and apoptosis have all been 
Table 8 Effect of coadministered drugs on rosuvastatin systemic exposure

\begin{tabular}{|c|c|c|c|}
\hline \multirow{2}{*}{$\begin{array}{l}\text { Coadministered drug and dosing } \\
\text { regimen }\end{array}$} & \multicolumn{3}{|l|}{ Rosuvastatin } \\
\hline & Dose $(\mathrm{mg})^{\mathrm{a}}$ & Change in $\mathrm{AUC}^{\mathrm{b}}$ & Change in $\mathrm{C}_{\max }^{\mathrm{b}}$ \\
\hline $\begin{array}{l}\text { Cyclosporine - stable dose required } \\
\text { (75-200 mg twice daily) }\end{array}$ & $\begin{array}{l}10 \text { mg daily for } \\
10 \text { days }\end{array}$ & $\uparrow 7$-foldc & $\uparrow$ II-foldc \\
\hline Gemfibrozil 600 mg twice daily for 7 days & $80 \mathrm{mg}$ & $\uparrow$ I.9-fold ${ }^{c}$ & $\uparrow 2.2$-fold ${ }^{c}$ \\
\hline $\begin{array}{l}\text { Lopinavir/ritonavir combination } 400 \mathrm{mg} / 100 \mathrm{mg} \\
\text { twice daily for } 10 \text { days }\end{array}$ & $\begin{array}{l}20 \mathrm{mg} \text { daily for } \\
7 \text { days }\end{array}$ & $\uparrow 2$-fold ${ }^{c}$ & $\uparrow 5$-fold ${ }^{c}$ \\
\hline $\begin{array}{l}\text { Atazanavir/ritonavir combination } \\
300 \mathrm{mg} / 100 \mathrm{mg} \text { daily for } 7 \text { days }\end{array}$ & $10 \mathrm{mg}$ & $\uparrow 3$-foldc & $\uparrow 7$-fold ${ }^{c}$ \\
\hline $\begin{array}{l}\text { Tipranavir/ritonavir combination } 500 \mathrm{mg} / 200 \mathrm{mg} \\
\text { twice daily for II days }\end{array}$ & $10 \mathrm{mg}$ & $\uparrow 26 \%$ & $\uparrow 2$-fold \\
\hline $\begin{array}{l}\text { Fosamprenavir/ritonavir } 700 \mathrm{mg} / 100 \mathrm{mg} \text { twice } \\
\text { daily for } 7 \text { days }\end{array}$ & $10 \mathrm{mg}$ & $\uparrow 8 \%$ & $\uparrow 45 \%$ \\
\hline Fenofibrate $67 \mathrm{mg} 3$ times daily for 7 days & $10 \mathrm{mg}$ & $\uparrow 7 \%$ & $\uparrow 21 \%$ \\
\hline $\begin{array}{l}\text { Aluminum and magnesium hydroxide } \\
\text { combination antacid, administered } \\
\text { simultaneously }\end{array}$ & $40 \mathrm{mg}$ & $\downarrow 54 \% \mathrm{c}$ & $\downarrow 50 \%$ c \\
\hline The above, administered 2 hours apart & $40 \mathrm{mg}$ & $\downarrow 22 \%$ & $\downarrow 16 \%$ \\
\hline Erythromycin $500 \mathrm{mg} 4$ times daily for 7 days & $80 \mathrm{mg}$ & $\downarrow 20 \%$ & $\downarrow 31 \%$ \\
\hline Ketoconazole $200 \mathrm{mg}$ twice daily for 7 days & $80 \mathrm{mg}$ & $\uparrow 2 \%$ & $\downarrow 5 \%$ \\
\hline Itraconazole $200 \mathrm{mg}$ daily for 5 days & $10 \mathrm{mg}$ & $\uparrow 39 \%$ & $\uparrow 36 \%$ \\
\hline & $80 \mathrm{mg}$ & $\uparrow 28 \%$ & $\uparrow 15 \%$ \\
\hline Fluconazole $200 \mathrm{mg}$ daily for II days & $80 \mathrm{mg}$ & $\uparrow \mid 4 \%$ & $\uparrow 9 \%$ \\
\hline
\end{tabular}

Notes: aSingle dose unless otherwise noted; bMean ratio (with/without coadministered drug and no change $=$ I-fold) or \% change (with/without coadministered drug and no change $=0 \%$; symbols of $\uparrow$ and $\downarrow$ indicate the exposure increase and decrease, respectively; ' Clinically significant.

Abbreviations: AUC, area under the plasma concentration-time curve; $C_{\max }$, peak plasma concentration.

reported. Apoptosis of muscle cells - direct myotoxicity - has been described after acute statin exposure. ${ }^{383,388}$ Intracellular calcium overload and activation of caspase- 3 to initiate apoptosis is yet another proposed mechanism. ${ }^{389}$ Dolichol is needed for synthesis of $\alpha$-dystroglycan, a major protein in the skeletal muscle dystrophin-glycoprotein complex, and deficiencies have been linked to muscle dysfunction. Finally, some evidence also implicates immune involvement, which may persist after statin therapy is discontinued. ${ }^{390,391}$ Four detailed, well-referenced recent reviews of statin myotoxicity are available. ${ }^{392-395}$

In summary, it appears that the side effects of statins are just as multimechanistic, or "pleiotropic", as the beneficial actions. Despite these seemingly complex biochemical effects, in practice, the incidence of myopathy and glucose intolerance is far outweighed by the overall benefits of statins in general, and rosuvastatin in particular. ${ }^{396,397}$ Most serious events may be averted with careful monitoring and avoidance of drug interactions, but individual and genetic susceptibility can unfortunately not yet be predicted clinically. The overwhelming majority of patients tolerate rosuvastatin well. In JUPITER, there were no significant differences in myotoxicity between treatment and control groups.

\section{Conclusion}

The challenge of a rising sea of cardiovascular risk, threatening to reverse improved coronary death rates, is immense. The reality is that few individuals will sustain the necessary

Table 9 Effect of rosuvastatin coadministration with warfarin, digoxin, and an oral contraceptive

\begin{tabular}{|c|c|c|c|}
\hline \multirow[t]{2}{*}{ Rosuvastatin dosage regimen } & \multicolumn{3}{|l|}{ Coadministered drug } \\
\hline & Name and dose & Change in AUC & Change in $\mathbf{C}_{\max }$ \\
\hline \multirow[t]{2}{*}{$40 \mathrm{mg}$ daily for 10 days } & Warfarin $25 \mathrm{mg}$, single dose & R-Warfarin $\uparrow 4 \%$ & R-Warfarin $\downarrow$ I\% \\
\hline & & S-Warfarin $\uparrow 6 \%$ & S-Warfarin $0 \%$ \\
\hline $40 \mathrm{mg}$ daily for 12 days & Digoxin $0.5 \mathrm{mg}$, single dose & $\uparrow 4 \%$ & $\uparrow 4 \%$ \\
\hline \multirow[t]{3}{*}{$40 \mathrm{mg}$ daily for 28 days } & Oral contraceptive (EE 0.035 mg & EE $\uparrow 26 \%$ & $\mathrm{EE} \uparrow 25 \%$ \\
\hline & and NG $0.180,0.215$, and $0.250 \mathrm{mg}$ ) & NG $\uparrow 34 \%$ & NG $\uparrow 23 \%$ \\
\hline & daily for 21 days & & \\
\hline
\end{tabular}

Abbreviations: AUC, area under the plasma concentration-time curve; $\mathrm{C}_{\max }$, peak plasma concentration; EE, ethinyl estradiol; NG, norgestrel; R-warfarin and S-warfarin, referring to the stereoisomers. 
lifestyle and behavioral changes to lower their risk, and this is amply reflected by the dismal success in weight control. Obesity drives the dual epidemics of diabetes and CHD. Primary prevention, sometimes regarded as an illusion, is only effective if it is done early and intensively. When lifestyle modification fails, reduction of elevated risk factors through pharmacological means is imperative, because by the time they are evident, atherosclerotic processes are already advanced. If we are to stem the tide, simply waiting for a cardiovascular event or diagnosis will no longer suffice.

Asymptomatic individuals randomized in the JUPITER study, many similar to those in the general population, bore a considerable cardiovascular burden, even though they were free from a formal diagnosis of heart disease, diabetes and dyslipidemia. Studies other than JUPITER confirm that higher values of CRP are associated with greater cardiovascular risk, which may assist in the decision of whether to treat or not. With the FDA approval for the use of rosuvastatin in JUPITEReligible patients with at least one additional cardiovascular risk factor, an additional choice became available to clinicians.

The prevalence of metabolic syndrome in JUPITER participants was about the same as in US adults at the present time. JUPITER demonstrated that within this population, those persons with elevations in CRP levels benefited from rosuvastatin therapy. While, as mentioned, some critics, observing that $41 \%$ of JUPITER participants had metabolic syndrome, suggested this diminished the value of the study. However, one can argue that the opposite was true, in that JUPITER demonstrated that rosuvastatin therapy in this syndrome, when CRP was elevated, was effective therapy. The prevalence of metabolic syndrome more closely follows the rise in level of visceral adiposity within the population, now averaging 53\%. ${ }^{398}$ At the moment, the highest prevalence of metabolic syndrome reported in an US subpopulation also stands at 53\%. ${ }^{127}$ The evidence that inflammation plays a critical role in the pathogenesis of components of metabolic syndrome is of high quality. ${ }^{198,199}$ A recent systematic review and meta-analysis of 87 studies involving 951,083 patients found that metabolic syndrome is associated with a 2-fold increase in risk of CVD, cardiovascular mortality, and stroke, and a 1.5 -fold rise in all-cause mortality. ${ }^{399}$

DeMazumder et $\mathrm{al}^{400}$ noted that the use of global risk assessment tools may result in denial of statin therapy to individuals at low risk when current guidelines are employed, while others with a high absolute risk may not benefit from statin therapy. These authors therefore suggested that statin therapy might be better allocated on the basis of randomized trial evidence rather than global risk scores. Nambi and Ballantyne ${ }^{401}$ proposed a formal protocol using the FRS, lifetime risk, and CRP, CIMT, calcium artery calcification burden, or genetic risk markers for progressive refinement of stratification. CRP measurements may be repeated easily, and are less involved than imaging, with no radiation exposure.

The reaction to JUPITER, many physicians will agree, has been most unusual. The rationale and findings are bracketed by many other independent investigations, but the final interpretation of the data presented is up to each physician. A repeat of JUPITER will probably not occur. The study is not perfect, and limitations are clear and well known. Controversies in medicine may endure for years without resolution. In the individual case, certainly other methods for risk stratification, such as CIMT measurement and coronary artery calcium score, are available. Processes bringing about alterations in each risk factor are different but overlap, and the information their changes bring to the physician's desk are complementary, not identical. Eventually a place for each will be found in the clinician's toolbox, but ultimately, the individual practitioner has the choice of where to reach in his armamentarium, the essence of the "art of medicine". It is encouraging to note that in blog comments written by individuals critical of some results and potential applications of JUPITER, when presented with specific cases, rosuvastatin is in fact being prescribed for high-risk individuals with elevated CRP values in primary prevention, indicating that patients' needs are being valued with higher priority than personal views.

Almost all JUPITER-eligible patients who would benefit from rosuvastatin have an alternative. Weight loss, especially in conjunction with exercise and dietary changes, are powerful techniques to lower cardiac risk and CRP levels ${ }^{197,213-222}$ and in fact would be preferred. The pervasive condition for which rosuvastatin has been found effective in JUPITER differs significantly from other diseases. This "illness" of unrecognized cardiovascular risk is diffuse, significant, difficult to quantitate, but deadly nonetheless. However, it is also largely self-inflicted, with a common cause in poor personal lifestyle choices. A recurring comment that ostensibly healthy people are being subjected to testing and side effects may be, in part, rooted in erroneously equating "asymptomatic" with ideal cardiovascular health - free of risk factors and a likelihood that none will appear in the near future ${ }^{402}-$ by the public. Perception of risk by patients is commonly inaccurate, and educational programs have been repeatedly recommended. ${ }^{403}$ 
The broader message of JUPITER is, first, it reminds us that the level of cardiovascular risk is currently oppressive, and greater than previously recognized when evaluated by LDL and global risk scores. Second, physicians must go on the offensive, delve into the population, and ferret out the risk, rather than wait for the risk to open their office door.

Today the clinician has a much greater amount of information and a wider variety of techniques from which to choose in order to evaluate individuals for primary prevention. Rosuvastatin will lower risk in JUPITER-eligible subpopulations, but also in many others selected differently for risk, even if one uses age for stratification, simply because the current level of risk is so high. Whatever markers or techniques are chosen, a fresh view of preventive care is before us, and action is now imperative. New guidelines in preparation will hopefully provide even greater direction in maximizing returns in primary prevention and improve future outcomes in our patients.

\section{Acknowledgment}

The author thanks Michelle Delaney for her suggestions, computer skills, and astuteness in the preparation of this manuscript.

\section{Disclosure}

The author states that he has not received any funds or favors from any private or public entity, corporation, agency, or other source related to this work.

\section{References}

1. USDHHS, National Center for Health Statistics. Second National Health and Nutrition Examination Survey (NHANES II). Hyattsville MD: CDC; 1976-1980.

2. USDHHS, National Center for Health Statistics. Second National Health and Nutrition Examination Survey (Continuous NHANES). Hyattsville MD: CDC; 1999-2002.

3. Young F, Capewell S, Ford ES, Critchley JA. Coronary mortality declines in the US between 1980 and 2000. Quantifying the contributions from primary and secondary prevention. Am J Prev Med. 2010; 39:228-234.

4. Ford ES, Capewell S. Coronary heart disease mortality among young adults in the US from 1980 to 2002: concealed leveling or mortality rates. J Am Coll Cardiol. 2007;50:2128-2132.

5. CDC National Center for Health Statistics. CDC mortality data, 2008: CDC latest release mortality data, 2005. www.cdc.gov/nchs/fastats/ deaths.htm. Accessed 2010 Oct 7.

6. Sacker A, Head J, Bartley M. Impact of coronary heart disease on health functioning in an aging population: are there differences according to socioeconomic position? Psychosom Med. 2008;70: 133-140.

7. Allender S, Scarborough P, Peto V, et al. European cardiovascular disease statistics 2008. European Heart Network, 2008. www.heartstats.org/uploads/documents\%5Cproof30NOV2007.pdf. Accessed 2010 Oct 7.

8. WHO Statistical Information System. Mortality data for ICD 10 codings. www.who.int/whosis/database/mort/download/ftp/morticd10.zip. Accessed 2010 Oct 7.
9. Ridker PM, Danielson E, Fonseca FA, et al; for JUPITER Study Group. Rosuvastatin to prevent vascular events in men and women with elevated C-reactive protein. $N$ Engl J Med. 2008;359: 2195-2207.

10. Thompson D, Pepys MB, Wood SP. The physiological structure of human C-reactive protein and its complex with phosphocholine. Structure. 1999;7:169-177.

11. Pepys MB, Hirschfield GM. C-reactive protein: a critical update. J Clin Invest. 2003;111:1805-1812.

12. Ridker PM, Cushman M, Stampfer MJ, Tracy RP, Hennekens CH. Inflammation, aspirin, and the risk of cardiovascular disease in apparently healthy men. N Engl J Med. 1997;336:973-979.

13. Hansson GK, Libby P. The immune response in atherosclerosis: a double-edged sword. Nat Rev Immunol. 2006;6:508-519.

14. Hwang SJ, Ballantyne CM, Sharrett AR, et al. Circulating adhesion molecules VCAM-1, ICAM-1, and E-selectin in carotid atherosclerosis and incident coronary heart disease cases: the Atherosclerosis Risk in Communities (ARIC) study. Circulation. 1997;96:4219-4225.

15. Ridker PM, Rifai N, Stampfer MJ, Hennekens CH. Plasma concentration of interleukin- 6 and the risk of future myocardial infarction among apparently healthy men. Circulation. 2000;101:1767-1772.

16. Ross R. Atherosclerosis-an inflammatory disease. $N$ Engl J Med. 1999;340:115-126.

17. Libby P, Ridker PM. Inflammation and atherothrombosis: from population biology and bench research to clinical practice. $\mathrm{JAm}$ Coll Cardiol. 2006;48:A33-A46.

18. Hansson GK. Inflammation, atherosclerosis, and coronary artery disease. $N$ Engl J Med. 2005;352:1685-1695.

19. Libby P, Nahrendorf M, Pittet MJ, Swirski FK. Diversity of denizens of the atherosclerotic plaque: not all monocytes are created equal. Circulation. 2008;117:3168-3170.

20. Mach F, Schoenbeck U, Bonnefoy JY, Pober J, Libby P. Activation of monocyte/macrophage functions related to acute atheroma complication by ligation of CD40. Induction of collagenase, stromelysin, and tissue factor. Circulation. 1997;96:396-399.

21. Spagnoli LG, Bonanno E, Mauriello A, et al. Multicentric inflammation in epicardial coronary arteries of patients dying of acute myocardial infarction. J Am Coll Cardiol. 2002;40:1579-1588.

22. Abbate A, Bonanno E, Mauriello A, et al. Widespread myocardial inflammation and infarct-related artery patency. Circulation. 2004; $110: 46-50$.

23. Lombardo A, Biasucci LM, Lanza GA, et al. Inflammation as a possible link between coronary and carotid plaque instability. Circulation. 2004; 109:3158-3163.

24. Nakajima T, Schulte S, Warrington KJ, et al. T-cell-mediated lysis of endothelial cells in acute coronary syndromes. Circulation. 2002; 105:570-575.

25. Blake GJ, Ridker PM. Inflammatory bio-markers and cardiovascular risk prediction. J Intern Med. 2002;252:283-294.

26. Esposito K, Giugliano D. Diet and inflammation: a link to metabolic and cardiovascular diseases. Eur Heart J. 2006;27:15-20.

27. Freedman JE, Loscalzo J. Platelet-monocyte aggregates: bridging thrombosis and inflammation. Circulation. 2002;105:2130-2132.

28. Steinhubl SR. Platelets as mediators of inflammation. Hematol Oncol Clin North Am. 2007;21:115-121.

29. Nettleton JA, Matijevic N, Follis JL, Folsom AR, Boerwinkle E. Associations between dietary patterns and flow cytometry-measured biomarkers of inflammation and cellular activation in the Atherosclerosis Risk in Communities (ARIC) Carotid Artery MRI Study. Atherosclerosis. 2010;212:260-267.

30. Libby P. Inflammation in atherosclerosis. Nature. 2002;420:868-874.

31. Ridker PM. Testing the inflammatory hypothesis of atherothrombosis: scientific rationale for the cardiovascular inflammation reduction trial (CIRT). J Thromb Haemost. 2009;7(Suppl 1):332-339.

32. Brugaletta S, Biasucci LM, Pinnelli M, et al. Novel anti-inflammatory effect of statins: reduction of CD4+CD28null T lymphocyte frequency in patients with unstable angina. Heart. 2006;92:249-250. 
33. Taubes G. Does Inflammation cut to the heart of the matter? Science. 2002;296:242-245.

34. Williams KJ, Tabas I. Atherosclerosis and inflammation. Science. 2002;297:521-522.

35. Ridker PM, Hennekens CH, Buring JE, Rifai N. C-reactive protein and other markers of inflammation in the prediction of cardiovascular disease in women. N Engl J Med. 2000;342:836-843.

36. Packard RRS, Libby P. Inflammation in atherosclerosis: from vascular biology to biomarker discovery and risk prediction. Clin Chem. 2008;43:24-38.

37. Altman R. Risk factors in coronary atherosclerosis ather-inflammation: the meeting point. Thrombosis J. 2003;1:4.

38. Vorchheimer DA, Fuster V. Inflammatory markers in coronary artery disease. Let prevention douse the flames. JAMA. 2001;286:2154-2156.

39. Ross R. The pathogenesis of atherosclerosis: a perspective for the 1990s. Nature. 1993;362:801-809.

40. Cybulsky MI, Gimbrone MA Jr. Endothelial expression of a mononuclear leukocyte adhesion molecule during atherogenesis. Science. 1991;251:788-791.

41. Bonetti PO, Lerman LO, Lerman A. Endothelial dysfunction: a marker of atherosclerotic risk. Arterioscler Thromb Vasc Biol. 2003;23: $168-175$.

42. Liuzzo G, Biasucci LM, Gallimore JL, et al. The prognostic value of C-reactive protein and serum amyloid A protein in severe unstable angina. N Engl J Med. 1994;331:417-424.

43. Biasucci LM, Vitelli A, Liuzzo G, et al. Elevated level of interleukin-6 in unstable angina. Circulation. 1996;94:874-877.

44. Libby P, Ridker PM, Maseri A. Inflammation and atherosclerosis. Circulation. 2002;105:1135-1143.

45. Wu KK, Aleksic N, Ballantyne Ch M, Ahn Ch, Juneja H, Boerwinkle E. Interaction between soluble thrombomodulin and Intercellular Adhesion Molecule-1 in predicting risk of coronary heart disease. Circulation. 2003;107:1729-1732.

46. Bhatt DL, Topol EJ. Need to test the arterial inflammation hypothesis. Circulation. 2002;106:136-140.

47. Kereiakes DJ. The fire that burns within. C-reactive protein. Circulation. 2003;107:373-374.

48. Ridker PM. High-sensitivity C-reactive protein, inflammation, and cardiovascular risk: from concept to clinical practice to clinical benefit. Am Heart J. 2004;148:S19-S26.

49. Dhingra R, Gona P, Nam B-H, et al. C-reactive protein, inflammatory conditions, and cardiovascular disease risk. Am J Med. 2007;120:1054-1062.

50. Gustafson B, Hammarstedt A, Andersson CX, Smith U. Inflamed adipose tissue: a culprit underlying the metabolic syndrome and atherosclerosis. Atheroscler Thromb Vasc Biol. 2007;27:2276-2283.

51. Liu Y, Yu H, Zhang Y, Zhao Y. TLRs are important inflammatory factors in atherosclerosis and may be a therapeutic target. Med Hypoth. 2008;70:314-316.

52. Virani SS, Polsani VR, Nambi ZV. Novel markers of inflammatioin in atherosclerosis. Curr Atheroscler Rep. 2008;10:164-170.

53. Peisajovich A, Marnell L, Mold C, Du Clos TW. C-reactive protein at the interface between innate immunity and inflammation. Expert Rev Clin Immunol. 2008;4:379-390.

54. Ikonomidis I, Stamatelopoulos K, Lekakis J, Vamvakou GD, Kremastinos DT. Inflammatory and non-invasive vascular markers: the multimarker approach for risk stratification in coronary artery disease. Atherosclerosis. 2008;199;3-11.

55. Otake H, Shite J, Shinke T, et al. Relation between plasma adiponectin, high sensitivity C-reactive protein, and coronary plaque components in patients with acute coronary syndrome. Am J Cardiol. 2008; 101:1-7.

56. Chamberlain J, Francis S, Brookes Z, et al. Interleukin-1 regulates multiples atherogenic mechanisms in response to fat feeding. PLoS ONE. 2009; 4:e5073.

57. Libby P, Okamoto Y, Rocha VZ, Folco E. Inflammation in atherosclerosis: transition from theory to practice. Circ J. 2010;74:213-220.
58. Ikeda U. Inflammation and coronary artery disease. Curr Vasc Pharmacol. 2003;1:65-70.

59. Heinisch RH, Zanetti CR, Comin F, Fernandes JL, Ramires JA, Serrano CV Jr. Serial changes in plasma levels of cytokines in patients with coronary artery disease. Vasc Health Risk Manag. 2005;1: 245-250.

60. Ridker PM. Inflammation, high-sensitivity C-reactive protein, and vascular protection. Tex Heart Inst J. 2010;37:40-41.

61. Curtiss LK. Reversing atherosclerosis? N Eng J Med. 2009;360: 1144-1146.

62. Tillett WS, Francis T Jr. Serological reactions in pneumonia with a nonprotein fraction of pneumococcus. J Exp Med. 1930;52:561-571.

63. Norata GD, Marchesi P, Pulakazhi VK, et al. Deficiency of the long pentraxin PTX3 promotes vascular inflammation and atherosclerosis. Circulation. 2009;120:699-708.

64. Hansson GK, Libby P, Schönbeck U, Yan ZQ. Innate and adaptive immunity in the pathogenesis of atherosclerosis. Circ Res. 2002;91: 281-291.

65. Abou-Raya A, Abou-Raya S. Inflammation: a pivotal link between autoimmune diseases and atherosclerosis. Autoimmun Rev. 2006;5: 331-337.

66. Sun J, Hartvigsen K, Chou M-Y, et al. Deficiency of antigen-presenting cell invariant chain reduces atherosclerosis in mice. Circulation. 2010; 122:808-820.

67. Okemefuna AI, Nan R, Miller A, Gor J, Perkins SJ. Complement factor $\mathrm{H}$ binds at two independent sites to $\mathrm{C}$-reactive protein in acute phase concentrations. J Biol Chem. 2010;285:1053-1065.

68. Bodman-Smith KB, Melendez AJ, Campbell I, Harrison PT, Allen JM, Raynes JG. C-reactive protein-mediated phagocytosis and phospholipase D signaling through the high-affinity receptor for immunoglobulin G (Fc $\gamma$ RI). Immunology. 2002;207:252-260.

69. Gabay C, Kushner I. Acute-phase proteins and other systemic responses to inflammation. $N$ Eng J Med. 1999;340:448-454.

70. Vigushin DM, Pepys MB, Hawkins PN. Metabolic and scintigraphic studies of radioiodinated human C-reactive protein in health and disease. J Clin Invest. 1993;91:1351-1357.

71. Lau DC, Dhillon B, Yan H, Szmitko PE, Verma S. Adipokines: molecular links between obesity and atheroslcerosis. Am J Physiol Heart Circ Physiol. 2005;288:H2031-H2041.

72. Brull DJ, Serrano N, Zito F, et al. Human CRP gene polymorphism influences CRP levels: implications for the prediction and pathogenesis of coronary heart disease. Arterioscler Thromb Vasc Biol. 2003;23:2063-2069.

73. Kathiresan S, Larson MG, Vasan RS, et al. Contribution of clinical correlates and $13 \mathrm{C}$-reactive protein gene polymorphisms to interindividual variability in serum C-reactive protein level. Circulation. 2006;113:1415-1423.

74. Shah T, Newcombe P, Smeeth L, et al. Ancestry as a determinant of mean population C-reactive protein values: implications for cardiovascular risk prediction. Circ Cardiovasc Genet. 2010;3: 436-444.

75. Rückerl R, Greven S, Ljungman P, et al; for the Airgene study. Air pollution and inflammation (interleukin-6, C-reactive protein, fibrinogen) in myocardial infarction survivors. Environ Health Perspect. 2007;115:1072-1080.

76. King DE, Egan BM, Woolson RF, Mainous AG III, Al-Solaiman Y, Jesri A. Effect of a high-fiber diet vs a fiber-supplemented diet on C-reactive protein level. Arch Intern Med. 2007;167: $502-506$.

77. Bo S, Durazzo M, Guidi S, et al. Dietary magnesium and fiber intakes and inflammatory and metabolic indicators in middle-aged subjects from a population-based cohort. Am J Clinical Nutrition. 2006;84:1062-1069.

78. King DE, Mainous AG III, Egan BM, Woolson RF, Geesey ME. Effect of psyllium fiber supplementation on C-reactive protein: the trial to reduce inflammatory markers (TRIM). Ann Fam Med. 2008;6:100-106. 
79. Ajani UA, Ford ES, Mokdad AH. Dietary fiber and C-reactive protein: findings from national health and nutrition examination survey data. J Nutr. 2004;134:1181-1185.

80. Zampelas A, Panagiotakos DB, Pitsavos C, et al. Associations between coffee consumption and inflammatory markers in healthy persons: the ATTICA study. Am J Clin Nutr. 2004;80:862-867.

81. Cavicchia PP, Steck SE, Hurley TF, et al. A new dietary inflammatory index predicts interval changes in serum high-sensitivity C-reactive protein. J Nutr. 2009;139:2365-2372.

82. Masters RC, Liese AD, Haffner SM, Wagenknecht LE, Hanley AJ. Whole and refined grain intakes are related to inflammatory protein concentrations in human plasma. J Nutr. 2010;140:587-594.

83. Esmaillzadah A, Kimiagar M, Mehrabi Y, Azadbakht L, Hu FB, Willett WC. Fruit and vegetable intakes, C-reactive protein, and the metabolic syndrome. Am J Clin Nutr. 2006:84:1489-2497.

84. Micallef MA, Munro IA, Garg ML. An inverse relationship between plasma n-3 fatty acids and C-reactive protein in healthy individuals. Eur J Clin Nutr. 2009;63:1154-1156.

85. Yen ML, Yang CY, Yen BL, et al. Increased high sensitivity C-reactive protein and neutrophil count are related to increased standard cardiovascular risk factors in healthy Chinese men. Int J Cardiol. 2006;110: 191-198.

86. Danesh J, Wheeler JG, Hirschfield GM, et al. C-reactive protein and other circulating markers of inflammation in the prediction of coronary heart disease. N Engl J Med. 2004;350:1387-1397.

87. Faber DR, van der Graaf Y, Westerink J, Visseren FLJ. Increased visceral adipose tissue mass is associated with increased C-reactive protein in patients with manifest vascular diseases. Atherosclerosis. 2010;212:274-280.

88. Imhof A, Froehlich M, Brenner H, et al. Effect of alcohol consumption on systemic markers of inflammation. Lancet. 2001;357:763-767.

89. Albert MA, Glynn RJ, Ridker PM. Alcohol consumption and plasma concentration of C-reactive protein. Circulation. 2003;107: 443-447.

90. Dreon DM, Slavin JL, Phinney SD. Oral contraceptive use and increased plasma concentration of C-reactive protein. Life Sci. 2003; $73: 1245-1252$

91. Frohlich M, Muhlberger N, Hanke H, et al. Markers of inflammation in women on different hormone replacement therapies. Ann Med. 2003 $35: 353-361$.

92. Black S, Kushner I, Samols D. C-reactive protein. J Biol Chem. 2004;279:48487-48490.

93. McDade TW, Rutherford JN, Adair L, Kuzawa C. Population differences in associations between C-reactive protein concentration and adiposity: comparison of young adults in the Philippines and the United States. Am J Clin Nutr. 2009;89:1237-1245.

94. Russell AI, Cunninghame Graham DS, Shepherd C, et al. Polymorphism at the C-reactive protein locus influences gene expression and predisposes to systemic lupus erythematosus. Hum Mol Genet. 2004; 13:137-147.

95. Jönsen A, Gunnarsson I, Gullstrand B, et al. Association between SLE nephritis and polymorphic variants of the CRP and Fc $\gamma$ RIIIa genes. Rheumatology (Oxford). 2007;46:1417-1421.

96. Edberg JC, Wu J, Langefeld CD, et al. Genetic variation in the CRP promoter: association with systemic lupus erythematosus (SLE). Hum Mol Genet. 2008;17:1147-1455.

97. Graf J, Scherzer R, Grunfeld C, Imboden J. Levels of C-reactive protein associated with high and very high cardiovascular risk are prevalent in patients with rheumatoid arthritis. PLoS ONE. 2009; 4:e6242.

98. Coventry BJ, Ashdown ML, Quinn MA, Markovic SN, YatomiClarke SL, Robinson AP. CRP identifies homeostatic immune oscillations in cancer patients: a potential treatment targeting tool? J Transl Med. 2009;7:102.

99. Morin-Papunen L, Rautio K, Ruokonen A, Hedberg P, Puukka M, Tapanainen JS. Metformin reduces serum C-reactive protein levels in women with polycystic ovary syndrome. J Clin Endocrinol Metab. 2003;88:4649-4654.
100. Tosi F, Dorizzi R, Castello R, et al. Body fat and insulin resistance independently predict increased serum C-reactive protein in hyperandrogenic women with polycystic ovary syndrome. Eur J Endocrinol. 2009;161:737-745.

101. Sathyapalan T, Kilpatrick ES, Coady AM, Atkin SL. The effect of atorvastatin in patients with polycystic ovary syndrome: a randomized double-blind placebo-controlled study. J Clin Endocrinol Metab. 2009; 94:103-108.

102. Hoeger KM. Polycystic ovary syndrome, inflammation and statins: do we have the right target? J Clin Endocrinol Metab. 2009;94:35-37.

103. De Beer F, Soutar AK, Baltz ML, Trayner IM, Feinstein A Pepys MB. Low density lipoprotein and very low density lipoprotein are selectively bound by aggregated C-reactive protein. $J$ Exp Med. 1982;156:230-242.

104. Zhang YX, Cliff WJ, Schoefl GI, Higgins G. Coronary C-reactive protein distribution: its relation to development of atherosclerosis. Atherosclerosis. 1999;145:375-379.

105. Pasceri V, Willerson JT, Yeh ET. Direct proinflammatory effect of C-reactive protein on human endothelial cells. Circulation. 2000;102: 2165-2168

106. Torzewski M, Rist C, Mortensen RF, et al. C-reactive protein in the arterial intima: role of C-reactive protein receptor-dependent monocyte recruitment in atherogenesis. Arterioscler Thromb Vasc Biol. 2000; 20:2094-2099.

107. Devaraj S, Davis B, Simon SI, Jialal I. CRP promotes monocyteendothelial cell adhesion via Fc $\gamma$ receptors in human aortic endothelial cells under static and shear flow conditions. Am J Physiol Heart Circ Physiol. 2006;291:H1170-H1176.

108. Rocker C, Manolov DE, Kuzmenkina EV, et al. Affinity of C-reactive protein toward FcgammaRI is strongly enhanced by the gamma-chain. Am J Pathol. 2007;170:755-763.

109. Schwartz R, Osborne-Lawrence S, Hahner L, et al. C-reactive protein downregulates endothelial $\mathrm{NO}$ synthase and attenuates reendothelialization in vivo in mice. Circ Res. 2007;100:1452-1459.

110. Szmitko PE, Verma S. C-reactive protein and reendothelialization: NO involvement. Circ Res. 2007;100:1405-1407.

111. Xing D, Hage FG, Chen YF, et al. Exaggerated neointima formation in human C-reactive protein transgenic mice is $\mathrm{IgG} \mathrm{Fc}$ receptor type 1 (Fc gamma RI)-dependent. Am J Pathol. 2008;172:22-30.

112. Salio M, Chimenti S, de Angelis N, et al. Cardioprotective function of the long pentraxin PTX3 in acute myocardial infarction. Circulation. 2008;117:1055-1064.

113. Van Vré EA, Bult H, Hoymans VY, van Tendeloo FI, Vrints CJ, Bosmans JM. Human C-reactive protein activates monocyte-derived dendritic cells and induces dendritic cell-mediated T-cell activation. Arterioscler Thromb Vasc Biol. 2008;28:511-518.

114. Fujita Y, Kakino A, Nishimichi N, et al. Oxidized LDL receptor LOX-1 binds to C-reactive protein and mediates its vascular effects. Clin Chem. 2009;55:285-294.

115. Filep JG. Platelets affect the structure and function of C-reactive protein. Circ Res. 2009;105:109-111.

116. Jin C, Lu L, Zhang RY, et al. Association of serum glycated albumin, C-reactive protein and ICAM-1 levels with diffuse coronary artery disease in patients with type 2 diabetes mellitus. Clin Chim Acta. 2009;408:45-49.

117. Ridker PM. C-reactive protein: eighty years from discovery to emergence as a major risk marker for cardiovascular disease. Clin Chem. 2009;55:209-215.

118. Geluk CA, Post WJ, Hillege HL, et al. C-reactive protein and angiographic characteristics of stable and unstable coronary artery disease: data from the prospective PREVEND cohort. Atherosclerosis. 2008;196:372-382.

119. Nabata A, Kuroki M, Ueba H, et al. C-reactive protein induces endothelial cell apoptosis and matrix metalloproteinase-9 production in human mononuclear cells: implications for the destabilization of atherosclerotic plaque. Atherosclerosis. 2008;196: 129-135. 
120. Scirica BM, Cannon CP, Sabatine MS, et al. Concentrations of C-reactive protein and B-type natriuretic peptide 30 days after acute coronary syndromes independently predict hospitalization for heart failure and cardiovascular death. Clin Chem. 2009;55:265-273.

121. Scirica BM, Morrow DA, Cannon CP, et al; Thrombolysis in Myocardial Infarction (TIMI) Study Group. Clinical application of C-reactive protein across the spectrum of acute coronary syndromes. Clin Chem. 2007;53:1800-1807.

122. Scirica BM, Morrow DA. Is C-reactive protein an innocent bystander or proatherogenic culprit? The verdict is still out. Circulation. 2006;113:2128-2134.

123. Verma S, Devaraj S, Jialal I. Is C-reactive protein an innocent bystander or proatherogenic culprit? C-reactive protein promotes atherothrombosis. Circulation. 2006;113:2135-2150.

124. Jialal I, Verma S, Devaraj S. Inhibition of endothelial nitric oxide synthase by C-reactive protein: clinical relevance. Clin Chem. 2009;55:206-208.

125. Guan H, Wang P, Hui R, Edin ML, Zeldin DC, Wang DW. Adenoassociated virus-mediated human C-reactive protein gene delivery causes endothelial dysfunction and hypertension in rats. Clin Chem. 2009;55:274-284.

126. Radjesh J, Bisoendial S, Boekholdt M, Vergeer M, Stroes ESG, Kastelein JJP. C-reactive protein is a mediator of cardiovascular disease. Eur Heart J. 2010;31:2087-2091.

127. Sinclair KA, Bogart A, Buchwald D, Henderson JA. The prevalence of metabolic syndrome and associated risk factors in Northern Plains and Southwest American Indians. Diabetes Care. 2010 Sep 23. [Epub ahead of print]

128. Kearney MT. Targeting the endothelium to prevent diabetes-related atherosclerosis. Diab Vasc Dis Res. 2010;7:177.

129. Ford ES, Giles WH, Myers GL, Mannino DM. Population distribution of high-sensitivity C-reactive protein among US men: findings from national health and nutrition examination survey 1999-2000. Clin Chem. 2003;49:686-690. http://www.clinchem.org/cgi/content/ full $/ 49 / 4 / 686$

130. Centers for Disease Control and Prevention. NHANES 1999-2000 public data release file documentation. http://www.cdc.gov/nchs/data/ nhanes/gendoc.pdf. Accessed 2010 Oct 18.

131. Rifai N, Ridker PM. Population distributions of C-reactive protein in apparently healthy men and women in the United States: implication for clinical interpretation. Clin Chem. 2003;49:666-669.

132. Woloshin S, Schwartz LM. Distribution of C-reactive protein values in the United States. N Eng J Med. 2005;352:1611-1613.

133. Kushner I, Rzewnicki W, Samols D. What does minor elevation of C-reactive protein signify? Am J Med. 2006;119:166.e17-166.e28.

134. Kao PC, Shiesh S-C, Wu T-J. Serum C-reactive protein as a marker for wellness assessment. Ann Clin Lab Sci. 2006;36:163-169.

135. Koenig W, Sund M, Frohlich M, et al. C-reactive protein, a sensitive marker of inflammation, predicts future risk of coronary heart disease in initially healthy middle-aged men: results from the MONICA (Monitoring Trends and Determinants in Cardiovascular Disease) Augsburg Cohort Study, 1984 to 1992. Circulation. 1999; 99:237-242.

136. Miller M, Zhan M, Havas S. High attributable risk of elevated C-reactive protein level to conventional coronary heart disease risk factors: the Third National Health and Nutrition Examination Survey. Arch Intern Med. 2005;165:2063-2068.

137. Greenfield JR, Samaras K, Jenkins AB, et al. Obesity is an important determinant of baseline serum C-reactive protein concentration in monozygotic twins, independent of genetic influences. Circulation. 2004;109:3022-3028.

138. Currie CJ, Poole CD, Conway P. Evaluation of the association between the first observation and the longitudinal change in C-reactive protein, and all-cause mortality. Heart. 2008;94:457-462.

139. Marsik C, Kazemi-Shirazi L, Schickbauer T, et al. C-reactive protein and all-cause mortality in a large hospital-based cohort. Clin Chem. 2008;54:343-349.
140. Kravitz BA, Corrada MM, Kawas CH. High levels of serum C-reactive protein are associated with greater risk of all-cause mortality, but not dementia, in the oldest-old: results from the 90+ study. J Am Ger Soc. 2009;57:641-646.

141. Wassel CL, Barrett-Connor E, Laughlin GA. Association of circulating C-reactive protein and interleukin-6 with longevity into the $80 \mathrm{~s}$ and 90s: The Rancho Bernardo Study. J Clin Endocrinol Metab. 2010;95:4748-4755.

142. Ridker PM, Rifai N, Rose L, Buring JE, Cook NR. Comparison of $\mathrm{C}$-reactive protein and low-density lipoprotein cholesterol levels in the prediction of first cardiovascular events. N Engl J Med. 2002;347: $1557-1565$.

143. Diaz JJ, Arguelles J, Malaga I, et al. C-reactive protein is elevated in the offspring of parents with essential hypertension. Arch Dis Child. 2007;92:304-308

144. Mancia G, de Backer G, Dominiczak A, et al. 2007 Guidelines for the management of arterial hypertension: The Task Force for the Management of Arterial Hypertension of the European Society of Hypertension (ESH) and of the European Society of Cardiology (ESC). Eur Heart J. 2007;28:1462-1536.

145. Ridker PM, Danielson E, Rifai N, Glynn RJ. Valsartan, blood pressure reduction, and C-reactive protein: primary report of the Val-MARC trial. Hypertension. 2006;48:73-79.

146. Sesso HD, Buring JE, Rifai N, Blake GJ, Gaziano JM, Ridker PM. $\mathrm{C}$-reactive protein and the risk of developing hypertension. JAMA. 2003;290:2945-2951.

147. Sathiyapriya V, Nandeesha H, Selvaraj N, Bobby Z, Agrawal A, Pavithran P. Association between protein-bound sialic acid and highsensitivity C-reactive protein in essential hypertension: a possible indication of underlying cardiovascular risk. Angiology. 2009;59: $721-726$.

148. Lande MB, Pearson TA, Vermilion RP, Auinger P, Fernandez ID. Elevated blood pressure, race/ethnicity, and C-reactive protein levels in children and adolescents. Pediatrics. 2008;122:1252-1257.

149. Black GJ, Rifai N, Buring JE, Ridker PM. Blood pressure, C-reactive protein, and risk of future cardiovascular events. Circulation. 2003;108:2993-2999.

150. Perticone F, Maio R, Sciacqua A, et al. Enodthelial dysfunction and C-reactive protein are risk factors for diabetes in essential hypertension. Diabetes. 2008;57:167-171.

151. Vardas PE, Marketou ME. CRP in non-dippers: new perspectives and old queries. J Human Hypertension. 2008;22:447-449.

152. Veerabhadrappa P, Diaz KM, Feairheller DL, et al. Enhanced blood pressure variability in a high cardiovascular risk group of African Americans: FIT4 Life Study. J Am Soc Hypertens. 2010;4: $187-195$

153. Iijima R, Byrne RA, Ndrepepa G, et al. Pre-procedural C-reactive protein levels and clinical outcomes after percutaneous coronary interventions with and without abciximab: pooled analysis of four ISAR trials. Heart. 2009;95:107-112.

154. Ishii H, Toriyama T, Aoyama T, et al. Prognostic values of C-reactive protein levels on clinical outcome after implantation of sirolimuseluting stents in patients on hemodialysis. Circ Cardiovasc Interv. 2009;2:513-518.

155. Iliodromitis EK, Kyrzopoulos S, Paraskevaidis IA, et al. Increased $\mathrm{C}$ reactive protein and cardiac enzyme levels after coronary stent implantation. Is there protection by remote ischaemic preconditioning? Heart. 2006;92:1821-1826.

156. Kangasniemi OP, Biancari F, Luukkonen J, et al. Preoperative C-reactive protein is predictive of long-term outcome after coronary artery bypass surgery. Eur J Cardiothorac Surg. 2006;29: 983-985.

157. Wypasek E, Undas A, Sniezek-Maciejewska M, et al. The increased plasma C-reactive protein and interleukin-6 levels in patients undergoing coronary artery bypass grafting surgery are associated with the interleukin-6-174G $>$ C gene polymorphism. Ann Clin Biochem. 2010;47:343-349. 
158. Lo B, Fijnheer R, Nierich AP, Bruins P, Kalkman CJ. C-reactive protein is a risk indicator for atrial fibrillation after myocardial revascularization. Ann Thorac Surg. 2005;79:1530-1535.

159. Kardys I, Knetsch AM, Bleumink GS, et al. C-reactive protein and risk of heart failure. The Rotterdam Study. Am Heart J. 2006;152:514-520.

160. Williams ES, Shah SJ, Ali S, Na BY, Schiller NB, Whooley MA. $\mathrm{C}$-reactive protein, diastolic dysfunction, and risk of heart failure in patients with coronary disease: Heart and Soul Study. Eur J Heart Fail. 2008;10:63-69.

161. Braunwald E. Biomarkers in heart failure. $N$ Engl J Med. 2008;358: 2148-2159.

162. Bozkurt B, Mann DL, Deswal A. Biomarkers of inflammation in heart failure. Heart Fail Rev. 2010;15:331-341.

163. Araujo JP, Lourenco P, Azevedo A, et al. Prognostic value of highsensitivity C-reactive protein in heart failure: a systematic review. J Cardiac Fail. 2009;15:256-266.

164. Collinson PO. Concentrations of C-reactive protein and B-type natriuretic peptide 30 days after acute coronary syndromes independently predict hospitalization for heart failure and cardiovascular death: just another brick in the wall? Clin Chem. 2009:55:203-205.

165. Lamblin N, Mouquet F, Hennache B, et al. High-sensitivity C-reactive protein: potential adjunct for risk stratification in patients with stable congestive heart failure. Eur Heart J. 2005;26:2245-2250.

166. Anand IS, Latini R, Florea VG, et al. C-reactive protein in heart failure: prognostic value and the effect of valsartan. Circulation. 2005;112:1428-1434.

167. Vasan RS, Sullivan LM, Roubenoff R, et al. Inflammatory markers and risk of heart failure in elderly subjects without prior myocardial infarction: the Framingham Heart Study. Circulation. 2003;107:1486-1491.

168. Conen D, Rexrode KM, Creager MA, Ridker PM, Pradhan AD. Metabolic syndrome, inflammation, and risk of symptomatic peripheral artery disease in women: a prospective study. Circulation 2009; 120:1041-1047.

169. Pande RL, Perlstein TS, Beckman JA, Creager MA. Association of insulin resistance and inflammation with peripheral arterial disease: the National Health and Nutrition Examination Survey, 1999 to 2004. Circulation. 2008;118(1):33-41.

170. Schlager O, Exner M, Mlekusch W, et al. C-reactive protein predicts future cardiovascular events in patients with carotid stenosis. Stroke. 2007;38:1263-1268.

171. Albert CM, Ma J, Rifai N, et al. Prospective study of C-reactive protein, homocysteine, and plasma lipid levels as predictors of sudden cardiac death. Circulation. 2002;4(105):2595-2599.

172. Spooner PM, Zipes DP. Sudden death predictors: an inflammatory association. Circulation. 2002;105:2574-2576.

173. Beri A, Contractor T, Khasnis A, Thakur R. Statins and the reduction of sudden cardiac death: antiarrhythmic or anti-ischemic effect? $\mathrm{Am}$ J Cardiovasc Drugs. 2010;10:155-164.

174. Corbalán R, Braun S, Pereira J, Navarrete C, Gonzalez I. C-reactive protein and atrial fibrillation: evidence for the presence of inflammation in the perpetuation of the arrhythmia. Int J Cardiol. 2006;108: 326-331.

175. Conen D, Ridker PM, Everett BM, et al. A multimarker approach to assess the influence of inflammation on the incidence of atrial fibrillation in women. Eur Heart J. 2010;31:1730-1736.

176. Marott SCW, Nordestgaard BG, Zacho J, et al. Does elevated C-reactive protein increase atrial fibrillation risk? A mendelian randomization of 47,000 individuals from the general population. J Am Coll Cardiol. 2010;56:789-795.

177. Blangy H, Sadoul N, Dousset B, et al. Serum BNP, hs-C-reactive protein, procollagen to assess the risk of ventricular tachycardia in ICD recipients after myocardial infarction. Europace. 2007;9:724-729.

178. Jeevanantham V, Singh N, Izuora K, D'souza JP, His DH. Correlation of high sensitivity $\mathrm{C}$-reactive protein and calcific aortic valve disease. Mayo Clin Proc. 2007;82:171-174.
179. Jones P, Davidson M, Stein E, et al. Comparison of the efficacy and safety of rosuvastatin versus atorvastatin, simvastatin, and pravastatin across doses (STELLAR* Trial). Am J Cardiol. 2003; 92:152-160

180. Ay C, Tengler T, Vormittag R, et al. Venous thromboembolism a manifestation of the metabolic syndrome. Haematologica. 2007;92: 374-380.

181. Quarck R, Nawrot T, Meyns B, Delcroix M. C-reactive protein a new predictor of adverse outcome in pulmonary arterial hypertension. J Am Coll Cardiol. 2009;53:1211-1218.

182. Soinio M, Marniemi J, Laakso M, et al. High-sensitivity C-reactive protein and coronary heart disease mortality in patients with type 2 diabetes: a 7-year follow-up study. Diabetes Care. 2006;29:329-333.

183. Marcovecchio ML, Giannini C, Widmer B, et al. C-reactive protein in relation to the development of microalbuminuria in type 1 diabetes. Diabetes Care. 2008;31:974-976.

184. Dehghan A, Kardys I, de Maat MPM, et al. Genetic variation, C-reactive protein levels, and incidence of diabetes. Diabetes. 2007; 56:872-878.

185. Kahn SE, Zinman B, Haffner SM, et al. Obesity is a major determinant of the association of C-reactive protein levels and the metabolic syndrome in type 2 diabetes. Diabetes. 2006;55:2357-2364.

186. Goldberg RB. Cytokine and cytokine-like inflammation markers, endothelial dysfunction, and imbalanced coagulation in development of diabetes and its complications. J Clin Endocrinol Metab. 2009;94:3171-3182.

187. Ridker PM, Pare G, Parker A, et al. Loci related to metabolic-syndrome pathways including LEPR, HNF1A, IL6R, and GCKR associate with plasma C-reactive protein: the Women's Genome Health Study. Am J Hum Genet. 2008;82:1185-1192.

188. Ridker PM, Buring JE, Cook NR, Rifai N. C-reactive protein, the metabolic syndrome, and risk of incident cardiovascular events: an 8-year follow-up of 14,719 initially healthy American women. Circulation. 2003;107;391-397.

189. Moreno-Navarrete JM, Martinez-Barricarte R, Catalan V, et al Complement factor $\mathrm{H}$ is expressed in adipose tissue in association with insulin resistance. Diabetes. 2010;59:200-209.

190. Jialal I. The role of the laboratory in the diagnosis of the metabolic syndrome. Am J Clin Pathol. 2009;132(2):161-162.

191. Steinberger J, Daniels SR, Eckel RH, et al; American Heart Association Atherosclerosis, Hypertension, and Obesity in the Young Committee of the Council on Cardiovascular Disease in the Young; Council on Cardiovascular Nursing; and Council on Nutrition, Physical Activity, and Metabolism. Progress and challenges in metabolic syndrome in children and adolescents: a scientific statement from the American Heart Association Atherosclerosis, Hypertension, and Obesity in the Young Committee of the Council on Cardiovascular Disease in the Young; Council on Cardiovascular Nursing; and Council on Nutrition, Physical Activity, and Metabolism. Circulation. 2009;119:628-647.

192. Cornier MA, Dabelea D, Hernandez TL, et al. The metabolic syndrome. Endocr Rev. 2008;29:777-822.

193. Suzuki T, Katz R, Jenny NS, et al. Metabolic syndrome, inflammation, and incident heart failure in the elderly: the Cardiovascular Health Study. Circ Heart Fail. 2008;1:242-248.

194. You T, Nicklas BJ, Ding J, et al. The metabolic syndrome is associated with circulating adipokines in older adults across a wide range of adiposity. J Gerontol A Biol Sci Med Sci. 2008;63:414-419.

195. Dai DF, Lin JW, Kao JH, et al. The effects of metabolic syndrome versus infectious burden on inflammation, severity of coronary atherosclerosis, and major adverse cardiovascular events. J Clin Endocrinol Metab. 2007;92:2532-2537.

196. Ye X, Yu Z, Li H, Franco OH, Liu Y, Lin X. Distributions of C-reactive protein and its association with metabolic syndrome in middle-aged and older Chinese people. J Am Coll Cardiol. 2007;49:1798-1805.

197. Pitsavos C, Panagiotakos DB, Tzima N, et al. Diet, exercise, and C-reactive protein levels in people with abdominal obesity: the ATTICA epidemiological study. Angiology. 2007;58:225-233. 
198. Devaraj S, Valleggi D, Siegel D, Jialal I. Role of C-reactive protein in contributing to increased cardiovascular risk in metabolic syndrome. Curr Atheroscler Rep. 2010;12:110-118.

199. Wang A, Nakayama T. Inflammation, a link between obesity and cardiovascular disease. Mediators Inflamm. 2010;2010:535918.

200. Alyan O, Metin F, Kacmaz F, et al. High levels of high sensitivity $\mathrm{C}$-reactive protein predict the progression of chronic rheumatic mitral stenosis. J Thromb Thrombolysis. 2009;28:63-69.

201. Lee HM, Le TV, Lopez VA, Wong ND. Association of C-reactive protein with reduced forced vital capacity in a nonsmoking US population with metabolic syndrome and diabetes. Diabetes Care. 2008;31:2000-2002.

202. Magnussen H, Watz H. Systemic inflammation in chronic obstructive pulmonary disease and asthma: relation with comorbidities. Proc Am Thorac Soc. 2009;6:648-651.

203. Eickhoff P, Valipour A, Kiss D, et al. Determinants of systemic vascular function in patients with stable chronic obstructive pulmonary disease. Am J Respir Crit Care Med. 2008;178:1211-1218.

204. Wahba IM, Mak RH. Obesity and obesity-initiated metabolic syndrome: mechanistic links to chronic kidney disease. JAm Soc Nephrol. 2007;2:550-562.

205. Chen HY, Chiu YL, Hsu SP, et al. Elevated C-reactive protein level in hemodialysis patients with moderate/severe uremic pruritus: a potential mediator of high overall mortality. QJM. 2010;103: 837-846.

206. Lahrach H, Ghalim N, Taki H, et al. Serum paraoxonase activity, high-sensitivity C-reactive protein, and lipoprotein disturbances in end-stage renal disease patients on long-term hemodialysis. $J$ Clin Lipidol. 2008;2:43-50.

207. Lui MM, Lam JC, Mak HK-F, et al. C-reactive protein is associated with obstructive sleep apnea independent of visceral obesity. Chest. 2009;135:950-956.

208. Schiza SE, Mermigkis C, Panagiotis, et al. C-reactive protein evolution in obstructive sleep apnoea patients under CPAP therapy. Eur J Clin Invest. 2010;40:968-975.

209. Zeka A, Sullivan JR, Vokonas PS, Sparrow D, Schwartz J. Inflammatory markers and particulate air pollution: characterizing the pathway to disease. Int J Epidemiol. 2006;35:1347-1354.

210. Dixon JB, Hayden MJ, Lambert GW, et al. Raised CRP Levels in obese patients: symptoms of depression have an independent positive association. Obesity. 2008;16:2010-2015.

211. Hak AE, Stehouwer CD, Bots ML, et al. Associations of C-reactive protein with measures of obesity, insulin resistance, and subclinical atherosclerosis in healthy, middle-aged women. Arterioscler Thromb Vasc Biol. 1999;19:1986-1991.

212. McLaughlin T, Abbasi F, Lamendola C, et al. Differentiation between obesity and insulin resistance in the association with C-reactive protein. Circulation. 2002;106:2908-2912.

213. Wee CC, Mukamal KJ, Huang A, Davis RB, McCarthy EP, Mittleman MA. Obesity and C-reactive protein levels among white, black, and hispanic US adults. Obesity. 2008;16:875-880.

214. Skinner AC, Steiner MJ, Henderson FW, Perrin EM. Multiple markers of inflammation and weight status: cross-sectional analyses throughout childhood. Pediatrics. 2010;125: e801-e809.

215. Puglisi MJ, Fernandez ML. Modulation of C-reactive protein, tumor necrosis factor $\alpha$, and adiponectin by diet, exercise, and weight loss. J Nutr. 2008;138:2293-2296.

216. Sacheck J. Pediatric obesity: an inflammatory condition? JPEN J Parenter Enteral Nutr. 2008;32:633-637.

217. Rankin JW, Turpyn AD. Low carbohydrate, high fat diet increases C-reactive protein during weight loss. J Am Coll Nutr. 2007;26: 163-169.

218. Selvin E, Paynter NP, Erlinger TP. The effect of weight loss on C-reactive protein: a systematic review. Arch Intern Med. 2007;167: 31-39.

219. Pope CA III. Particulate air pollution, C-reactive protein, and cardiac risk. Eur Heart J. 2001;22:1149-1150.
220. Nicklas BJ, You T, Pahor M. Behavioural treatments for chronic systemic inflammation: effects of dietary weight loss and exercise training. CMAJ. 2005;172:1199-1209.

221. Gentile M, Panico S, Rubba F, et al. Obesity, overweight, and weight gain over adult life are main determinants of elevated hsCRP in a cohort of Mediterranean women. Eur J Clin Nutr. 2010;64: 873-878.

222. Hamer M, Steptoe A. Prospective study of physical fitness, adiposity, and inflammatory markers in healthy middle-aged men and women. Am J Clin Nutr. 2009;89:85-89.

223. Welsh P, Polisecki E, Robertson M, et al. Unraveling the directional link between adiposity and inflammation: a bidirectional Mendelian randomization approach. $J$ Clin Endocrinol Metab. 2010;95: 93-99.

224. Hubel CA, Powers RW, Snaedal S, et al. C-reactive protein is elevated 30 years after eclamptic pregnancy. Hypertension. 2008;51: 1499-1505.

225. Lau B, Sharrett SR, Kingsley LA, et al. C-reactive protein is a marker for human immunodeficiency virus disease progression. Arch Intern Med. 2006;166:64-70.

226. Surtees PG, Wainwright NWJ, Boekholdt SM, Luben RN, Wareham NJ, Khaw KT. Major depression, C-reactive protein, and incident ischemic heart disease in healthy men and women. Psychosom Med. 2008;70:850-855.

227. Ridker PM. High-sensitivity C-reactive protein: potential adjunct for global risk assessment in the primary prevention of cardiovascular disease. Circulation. 2001;103:1813-1818.

228. Pankow JS, Folsom AR, Cushman M, et al. Familial and genetic determinants of systemic markers of inflammation: the NHLBI family heart study. Atherosclerosis. 2001;154:681-689.

229. Lee CC, You NC, Song Y, et al. Relation of genetic variation in the gene coding for C-reactive protein with its plasma protein concentrations: findings from the Women's Health Initiative Observational Cohort. Clin Chem. 2009;55(2):351-360.

230. Kelley-Hedgepeth A, Lloyd-Jones DM, Colvin A, et al. Ethnic differences in C-reactive protein concentrations. Clin Chem. 2008;54: 1027-1037.

231. Smith GD, Ebrahim S. Mendelian randomization: can genetic epidemiology contribute to understanding environmental determinants of disease? Int J Epidemiol. 2003;32:1-22.

232. Zacho J, Tybjaerg-Hansen A, Jensen JS, Grande P, Sillesen H, Nordestgaard BG. Genetically elevated C-reactive protein and ischemic vascular disease. N Engl J Med. 2008;359:1897-1908.

233. Smith DG. Capitalizing on Mendelian randomization to assess the effects of treatments. $J$ R Soc Med. 2007;100:432-435.

234. Sheehan NA, Didelez V, Burton PR, Tobin MD. Mendelian randomisation and causal inference in observational epidemiology. PLoS Med. 2008;5:e177.

235. Elliott P, Chambers JC, Zhang W, et al. Genetic loci associated with $\mathrm{C}$-reactive protein levels and risk of coronary heart disease. JAMA. 2009;302:37-48.

236. Smith GD, Ebrahim S. Mendelian randomization: prospects, potentials, and limitations. Int J Epidemiol. 2004;33:30-42.

237. Emerging Risk Factors Collaboration, Kaptoge S, Di Angelantonio E, Lowe G, et al. C-reactive protein concentration and risk of coronary heart disease, stroke, and mortality: an individual participant metaanalysis. Lancet. 2010;375:132-140.

238. Danesh J, Kaptoge S, Mann AG, et al. Long-term interleukin-6 levels and subsequent risk of coronary heart disease: two new prospective studies and a systematic review. PLoS Med. 2008;5:e78.

239. Clarke R, Emberson JR, Breeze E, et al. Biomarkers of inflammation predict both vascular and non-vascular mortality in older men. Eur Heart. 2008;29:800-809.

240. Heikkila K, Harris R, Lowe G, et al. Associations of circulating $\mathrm{C}$-reactive protein and interleukin-6 with cancer risk: findings from two prospective cohorts and a meta-analysis. Cancer Causes Control. 2009;20:15-26. 
241. Habersberger J, Eisenhardt S, Peter K. C-reactive protein measurement and cardiovascular disease. Original Text. Lancet. 2010;9720: 1078 .

242. Ji SR, Wu Y, Zhu L, et al. Cell membranes and liposomes dissociate $\mathrm{C}$-reactive protein (CRP) to form a new, biologically active structural intermediate: mCRP(m). FASEB J. 2007;21:284-294.

243. Molins B, Peña E, Vilahur G, Mendieta C, Slevin M, Badimon L. $\mathrm{C}$-reactive protein isoforms differ in their effects on thrombus growth. Arterioscler Thromb Vasc Biol. 2008;28:2239-2246.

244. Eisenhardt SU, Habersberger J, Murphy A, et al. Dissociation of pentameric to monomeric C-reactive protein on activated platelets localizes inflammation to atherosclerotic plaques. Circ Res. 2009; 105:128-137.

245. Ji SR, Ma L, Bai CJ, et al. Monomeric C-reactive protein activates endothelial cells via interaction with lipid raft microdomains. FASEBJ. 2009;23:1806-1816.

246. Ridker PM, Rifai N, Clearfield M, et al. Measurement of C-reactive protein for the targeting of statin therapy in the primary prevention of acute coronary events. N Engl J Med. 2001;344:1959-1965.

247. Tuzcu EM, Kapadia SR, Tutar E, et al. High prevalence of coronary atherosclerosis in asymptomatic teenagers and young adults: evidence from intravascular ultrasound. Circulation. 2001;103: $2705-2710$.

248. Ridker PM, Cannon CP, Morrow D, et al; Atorvastatin Evaluation and Infection Therapy-Thrombolysis in Myocardial Infarction 22 (PROVE IT - TIMI 22) Investigators. C-reactive protein levels and outcomes after statin therapy. $N$ Engl J Med. 2005;352:20-28.

249. De Beer FC, Hind CR, Fox KM, et al. Measurement of serum $\mathrm{C}$-reactive protein concentration in myocardial ischaemia and infarction. Br Heart J. 1982;47:239-243.

250. Haverkate F, Thompson SG, Pyke SD, et al. Production of C-reactive protein and risk of coronary events in stable and unstable angina. European Concerted Action on Thrombosis and Disabilities Angina Pectoris Study Group. Lancet. 1997;349:462-466.

251. Niccoli G, Biasucci LM, Biscione C, et al. Independent prognostic value of C-reactive protein and coronary artery disease extent in patients affected by unstable angina. Atherosclerosis. 2008;196: 779-785.

252. Ridker PM, Cushman M, Stampfer MJ, et al. Plasma concentration of C-reactive protein and risk of developing peripheral vascular disease. Circulation. 1998;97:425-428.

253. Nissen SE, Tuzcu EM, Schoenhagen P, et al. Statin therapy, LDL cholesterol, C-reactive protein, and coronary artery disease. $N$ Engl J Med. 2005;352:29-38.

254. Hemingway H, Philipson P, Chen R, Fitzpatrick NK, Damant J, et al. Evaluating the quality of research into a single prognostic biomarker: a systematic review and meta-analysis of 83 studies of C-reactive protein in stable coronary artery disease. PLoS Med. 2010;7: e1000286.

255. Boekholdt SM, Hack CE, Sandhu MS, et al. C-reactive protein levels and coronary artery disease incidence and mortality in apparently healthy men and women: the EPIC-Norfolk prospective population study 1993-2003. Atherosclerosis. 2006;187:415-422.

256. Cook NR, Buring JE, Ridker PM. The effect of including C-reactive protein in cardiovascular risk prediction models for women. Ann Intern Med. 2006;145:21-29.

257. Genest J, McPherson R, Frohlich J, et al. 2009 Canadian Cardiovascular Society/Canadian guidelines for the diagnosis and treatment of dyslipidemia and prevention of cardiovascular disease in the adult - 2009 recommendations. Can J Cardiol. 2009;25:567-579.

258. Albert MA, Glynn RJ, Ridker PM. Plasma concentration of C-reactive protein and the calculated Framingham Coronary Heart Disease Risk Score. Circulation. 2003;108:161-165.

259. Ridker PM, Rifai N, Cook NR, Bradwin G, Buring JE. Non-HDL cholesterol, apolipoproteins A-I and B100, standard lipid measures, lipid ratios, and CRP as risk factors for cardiovascular disease in women. JAMA. 2005;294:326-333.
260. Shah T, Casas JP, Cooper JA, et al. Critical appraisal of CRP measurement for the prediction of coronary heart disease events: new data and systematic review of 31 prospective cohorts. Int J Epidemiol. 2009; 38:217-231.

261. Wald DS, Kasturiratne A, Bestwick JP. The value of C-reactive protein in screening for future coronary heart disease events. J Med Screen. 2009;16:212-214.

262. Lakoski SG, Greenland P, Wong ND, Schreiner PJ, et al. Coronary artery calcium scores and risk for cardiovascular events in women classified as "low risk" based on Framingham risk score: the MultiEthnic Study of Atherosclerosis (MESA). Arch Intern Med. 2007; 167:2437-2442.

263. Ridker PM, Buring JE, Rifai N, Cook NR. Development and validation of improved algorithms for the assessment of global cardiovascular risk in women: the Reynolds Risk Score. JAMA. 2007;297: 611-619.

264. Wilson PW, Pencina M, Jacques P, Selhub J, D’Agostino Sr R, O'Donnell CJ. C-reactive protein and reclassification of cardiovascular risk in the Framingham Heart Study. Circ Cardiovasc Qual Outcomes 2008;1:92-97.

265. Ridker PM, Paynter NP, Rifai N, Gaziano JM, Cook NR. C-reactive protein and parental history improve global cardiovascular risk prediction: the Reynolds Risk Score for Men. Circulation. 2008;118: 2243-2251.

266. Cook NR. The case for C-reactive protein as a risk marker for coronary heart disease. Ann Intern Med. 2010;152:406.

267. Cook NR, Ridker PM. Advances in measuring the effect of individual predictors of cardiovascular risk: the role of reclassification measures Ann Intern Med. 2009;50:795-802.

268. Ridker PM, MacFadyen J, Libby P, Glynn RJ. Relation of baseline high-sensitivity C-reactive protein level to cardiovascular outcomes with rosuvastatin in the Justification for Use of statins in Prevention: an Intervention Trial Evaluating Rosuvastatin (JUPITER). Am J Cardiol. 2010;106:204-209.

269. Slejko JF, Page RL II, Sullivan PW. Implications of Jupiter prevention in adults with elevated C-reactive protein: statin therapy is costeffective for vascular event. J Am Coll Cardiol. 2010;55: A131.E1229.

270. Rao AD, Milbrandt EB. To JUPITER and beyond: statins, inflammation, and primary prevention. Critical Care. 2010;14:310.

271. MacDonald GP. Cost-effectiveness of rosuvastatin for primary prevention of cardiovascular events according to Framingham Risk Score in patients with elevated C-reactive protein. J Am Osteopath Assoc. 2010;110:427-436

272. Danesh J, Collins R, Appleby P, Peto R. Association of fibrinogen, C-reactive protein, albumin, or leukocyte count with coronary heart disease: meta-analyses of prospective studies. JAMA. 1998;279: 1477-1482.

273. Danesh J, Whincup P, Walker M, et al. Low grade inflammation and coronary heart disease: prospective study and updated meta-analyses. BMJ. 2000;321:199-204

274. Nambi V, Ballantyne CM. Utility of statin therapy using highsensitivity C-reactive protein as an indicator of coronary heart disease risk. Curr Atheroscler Rep. 2005;7:22-28.

275. Ridker PM. High-sensitivity C-reactive protein and cardiovascular risk: rationale for screening and primary prevention. Am J Cardiol. 2003;92:17K-22K.

276. Roche VF. Antihyperlipidemic statins: a self-contained, clinically relevant medicinal chemistry lesson. Am J Pharm Educ. 2005;69: 546-560.

277. Istvan ES, Deisenhofer J. Structural mechanism for statin inhibition of HMG-CoA reductase. Science. 2001;292:1160-1164.

278. Hamelin BA, Turgeon J. Hydrophilicity/lipophilicity: relevance for the pharmacology and clinical effects of HMG-CoA reductase inhibitors Trends Pharmacol Sci. 1998;19:26-37.

279. McTaggart F. Comparative pharmacology of rosuvastatin. Atheroscler Suppl. 2003;4:9-14. 
280. Kapur NK. Rosuvastatin: a highly potent statin for the prevention and management of coronary artery disease. Expert Rev Cardiovasc Ther. 2007;5:161-175.

281. Holtzman CW, Wiggins BS, Spinler SA. Role of P-glycoprotein in statin drug interactions. Pharmacotherapy. 2006;26:1601-1607.

282. Kostapanos MS, Haralampos J, Elisaf MS. Rosuvastatin-associated adverse effects and drug-drug interactions in the clinical setting of dyslipidemia. Am J Cardiovasc Drugs. 2010;10:11-28.

283. Baigent C, Keech A, Kearney PM, et al; Cholesterol Treatment Trialists' (CTT) Collaborators. Efficacy and safety of cholesterollowering treatment: prospective meta-analysis of data from 90,056 participants in 14 randomized trials of statins. Lancet. 2005;366:1267-1278.

284. McKenney JM. Pharmacologic options for aggressive low-density lipoprotein cholesterol lowering: benefits versus risks. Am J Cardiol. 2005;96:60E-66E.

285. The Galaxy Program. http://www.galaxyprogramme.org/ about-galaxy/?itemId=2592383. Accessed 2010 Oct 18

286. Crouse JR III, Raichlen JS, Riley WA, et al; METEOR study group. Effect of rosuvastatin on progression of carotid intima-media thickness in low-risk individuals with subclinical atherosclerosis. JAMA. 2007; 297:1344-1353.

287. Crouse JR III, Bots ML, Evans GW, et al. Does baseline carotid intima-media thickness modify the effect of rosuvastatin when compared with placebo on carotid intima-media thickness progression? The METEOR study. Eur J Cardiovasc Prev Rehabil. 2010;17:223-229.

288. Kjekshus J, Apetrei E, Barrios V, et al. Rosuvastatin in older patients with systolic heart failure. $N$ Engl $J$ Med. 2007;357: 2248-2261.

289. McMurray JJV, Kjekshus J, Gullestad L, et al; CORONA Study Group. Effects of statin therapy according to plasma high-sensitivity C-reactive protein concentration in the Controlled Rosuvastatin Multinational trial in Heart Failure (CORONA). A retrospective analysis. Circulation. 2009;120:2188-2196.

290. Gissi-HF Investigators, Tavazzi L, Maggioni AP, Marchioli R, et al. Effect of rosuvastatin in patients with chronic heart failure (the GISSI-HF trial): a randomised, double-blind, placebo-controlled trial. Lancet. 2008;372:1231-1239.

291. Van der Harst P, de Boer RA. Statins in the treatment of heart failure. Circ Heart Fail. 2010;3:462-464.

292. Fellström BC, Jardine AG, Schmieder RE, et al. Rosuvastatin and cardiovascular events in patients undergoing hemodialysis. $N$ Eng $J$ Med. 2009;373:1175-1182.

293. Narla V, Blaha MJ, Blumenthal RS, Michos ED. The JUPITER and AURORA clinical trials for rosuvastatin in special primary prevention populations: perspectives, outcomes, and consequences. Vasc Health Risk Manag. 2009;5:1033-1042.

294. Nissen SE, Nicholls SJ, Sipahi I, et al. Effect of very high-intensity statin therapy on regression of coronary atherosclerosis: the ASTEROID trial. JAMA. 2006;295:1556-1565.

295. Ballantyne CM, Raichlen JS, Nicholls S, et al; ASTEROID Investigators. Effect of rosuvastatin therapy on coronary artery stenoses assessed by quantitative coronary angiography: a study to evaluate the effect of rosuvastatin on intravascular ultrasoundderived coronary atheroma burden. Circulation. 2008;117: 2458-2466.

296. Mack WJ, Xiang M, Selzer RH, Hodis HN. Serial quantitative coronary angiography and coronary events. Am Heart J. 2000;139: 993-999.

297. Buchwald H, Matts JP, Fitch LL, et al; Program on the Surgical Control of the Hyperlipidemias (POSCH) Group. Changes in sequential coronary arteriograms and subsequent coronary events. JAMA. 1992;268:1429-1433.

298. Fonseca FAH, Izar MCO. Primary prevention of vascular events in patients with high levels of C-reactive protein: the JUPITER Study. Expert Rev Cardiovasc Ther. 2009;7:1041-1056.
299. Libby P, Ridker PM. Novel inflammatory markers of coronary risk: theory versus practice. Circulation. 1999;100:1148-1150.

300. Lemieux I, Pascot A, Prud'homme D, Almeras N, et al. Elevated C-reactive protein: another component of the atherothrombotic profile of abdominal obesity. Arterioscler Thromb Vasc Biol. 2001;21: 961-967.

301. Ridker PM, Rifai N, Pfeffer MA, et al. Inflammation, pravastatin, and the risk of coronary events after myocardial infarction in patients with average cholesterol levels. Cholesterol and Recurrent Events (CARE) Investigators. Circulation. 1998;98:839-844.

302. Ridker PM; JUPITER Study Group. Rosuvastatin in the primary prevention of cardiovascular disease among patients with low levels of low-density lipoprotein cholesterol and elevated high-sensitivity C-reactive protein: rationale and design of the JUPITER trial. Circulation. 2003;108:2292-2297.

303. Ridker PM, Fonseca FAH, Genest J, et al; JUPITER Trial Study Group. Baseline characteristics of participants in the JUPITER Trial, a randomized placebo-controlled primary prevention trial of statin therapy among individuals with low low-density lipoprotein cholesterol and elevated high-sensitivity C-reactive protein. Am J Cardiol. 2007;100:1659-1664.

304. De Lorgeril M, Salen P, Martin JL, Monjaud I, Delaye J, Mamelle N. Mediterranean diet, traditional risk factors, and the rate of cardiovascular complications after myocardial infarction - final report of the Lyon Diet Heart Study. Circulation. 1999;99:779-785.

305. Rembold CM. To statin or to non-statin in coronary disease - considering absolute risk is the answer. Atherosclerosis. 2007;195:1-6.

306. Everett BM, Ridker PM. Using inflammatory biomarkers to guide lipid therapy. Curr Cardiovasc Risk Reports. 2008;2:29-34.

307. Kritek P, Campion EW. JUPITER Clinical Directions - polling results. N Eng J Med. 2009;360:e14.

308. Spatz ES, Canavan ME, Desai MM. From here to JUPITER. Identifying new patients for statin therapy using data from the 1999-2004 National Health and Nutrition Examination Survey. Circ Qual Outcomes. 2009;2:41-48.

309. Michos ED, Blumenthal RS. Prevalence of the JUPITER (Justification for the Use of Statins in Primary Prevention: an Intervention Trial Evaluating Rosuvastatin) Study. J Am Coll Cardiol. 2009;53: 931-935.

310. Ridker PM. The JUPITER trial. Results, controversies, and implications for prevention. Circ Cardiovasc Qual Outcomes. 2009;2:279-285.

311. Ridker PM, MacFadyen JG, Fonseca FAH, et al; JUPITER Study Group. Number needed to treat with rosuvastatin to prevent first cardiovascular events and death among men and women with low low-density lipoprotein cholesterol and elevated high-sensitivity C-reactive protein. Justification for the Use of statins in Prevention: an Intervention Trial Evaluation Rosuvastatin (JUPITER). Circ Cardiovasc Qual Outcomes. 2009;2:616-623.

312. Yang EY, Nambi V, Tang Z, et al. Clinical implications of JUPITER (Justification for the Use of statins in Prevention: an Intervention Trial Evaluating Rosuvastatin) in a US population: insights from the ARIC (Atherosclerosis Risk in Communities) study. J Am Coll Cardiol. 2009;54:2388-2395.

313. Vaccarino V, Bremmer JD, Kelley ME. JUPITER. A few words of caution. Circ Cardiovasc Qual Outcomes. 2009;2:286-288.

314. Kones R. Recent advances in the management of chronic stable angina. II. Anti-ischemic therapy, options for refractory angina, risk factor reduction, and revascularization. Vasc Health Risk Manag. 2010;6:749-774.

315. Eyre H, Kahn R, Robertson RM. Preventing cancer, cardiovascular disease, and diabetes: a common agenda for the American Cancer Society, the American Diabetes Association, and the American Heart Association. Diabetes Care. 2004;27:1812-1824.

316. Levi J, Segal LM, Juliano C. Prevention for a healthier America: investments in disease prevention yield significant savings, stronger communities: Trust for America's Health. Issue Report 2008 Jul. http:// healthyamericans.org/reports/prevention08/. Accessed 2010 Sep 1. 
317. Heart Protection Study Collaborative Group. Statin cost-effectiveness in the United States for people at different vascular risk levels. Circ Cardiovasc Qual Outcomes. 2009;2:65-72.

318. Accad M, Fred HL. Is JUPITER also a God of primary prevention? Tex Heart Inst J. 2010;37:6-7.

319. Kappagoda CT, Amsterdam EA. Another look at the results of the JUPITER trial. Am J Cardiol. 2009;104:1603-1605.

320. Ridker PM, Danielson E, Fonseca FA, et al. Reduction in C-reactive protein and LDL cholesterol and cardiovascular event rates after initiation of rosuvastatin: a prospective study of the JUPITER trial. Lancet. 2009;373:1175-1182.

321. Despres JP. Bringing JUPITER down to Earth. Lancet. 2009;373 1147-1148.

322. Kostapanos MS, Milionis HJ, Elisaf MS. An overview of the extra-lipid effects of rosuvastatin. J Cardiovasc Pharmacol Ther. 2008;13:157-174.

323. Kendrick M. Should women be offered cholesterol lowering drugs to prevent cardiovascular disease? No. BMJ. 2007;334:983.

324. Eisenberg T, Wells M. Statins and adverse cardiovascular events in moderate-risk females: a statistical and legal analysis with implications for FDA preemption claims. J Empir Leg Stud. 2008;5:507-550

325. Rosenberg H, Allard D. Women and statin use: a women's health advocacy perspective. Scand Cardiovasc J. 2008;42:268-273.

326. Mora S, Glynn RJ, Hsia J, MacFadyen JG, Genest J, Ridker PM. Statins for the primary prevention of cardiovascular events in women with elevated high-sensitivity C-reactive protein or dyslipidemia: results from the Justification for the Use of Statins in Prevention: an Intervention Trial Evaluating Rosuvastatin (JUPITER) and metaanalysis of women from primary prevention trials. Circulation. 2010;121: 1069-1077.

327. Duvernoy CS, Blumenthal R. The numbers are in: statins for the primary prevention of cardiovascular disease in women. Circulation 2010;121:1063-1065.

328. Highlights of prescribing information: Crestor (rosuvastatin calcium) tablets. http://www.accessdata.fda.gov/drugsatfda_docs/ label/2010/021366s016lbl.pdf. Accessed 2010 Apr 16.

329. Kaul S, Morrissey RP, Diamond GA. By Jove! What is a clinician to make of JUPITER? Arch Int Med. 2010;170:1073-1077.

330. Jupiter criticism addressed again in more detail. 2010 Oct 1. http://www. theheart.org/article/1130113.do. Accessed 2010 Oct 15

331. Bassler D, Briel M, Montori VM, et al; STOPIT-2 Study Group. Stopping randomized trials early for benefit and estimation of treatment effects: systematic review and meta-regression analysis. JAMA. 2010 303:1180-1187.

332. Montori VM, Devereaux PJ, Adhikari NKJ, et al. Randomized trials stopped early for benefit: a systematic review. JAMA 2005;294:2203-2209.

333. Pocock SJ. Current controversies in data monitoring for clinical trials. Clin Trials. 2006;3:513-521.

334. McCatney M. Leaping to conclusions. BMJ. 2008;336:1213-1214.

335. Department of Health and Human Services, United States Food and Drug Administration, Center for Drug Evaluation and Research. Transcript for the 2009 Dec 15, Meeting of the Endocrinologic and Metabolic Drugs Advisory Committee. http://www.fda.gov/ downloads/AdvisoryCommittees/CommitteesMeetingMaterials/ Drugs/EndocrinologicandMetabolicDrugsAdvisoryCommittee/ UCM200611.pdf. Accessed 2010 Oct 7.

336. De Lorgeril M, Salen P, Abramson J, et al. Cholesterol lowering, cardiovascular diseases, and the rosuvastatin-JUPITER controversy: a critical reappraisal. Arch Intern Med. 2010;170:1032-1036.

337. De Lorgeril M. Answers to R. Ridker by M. de Lorgeril. 2010 Jun 30. http://michel.delorgeril.info/dwnl/JUPITER/2010_Answers-toRidker-by-de-Lorgeril.pdf. Accessed 2010 Aug 15.

338. Glynn RJ, Danielson E, Fonseca FAH, et al. A randomized trial of rosuvastatin in the prevention of venous thromboembolism. $N$ Engl J Med. 2009;360:1851-1861.
339. Ridker PM, Macfadyen J, Cressman M, Glynn RJ. Efficacy of rosuvastatin among men and women with moderate chronic kidney disease and elevated high-sensitivity C-reactive protein: a secondary analysis from the JUPITER (Justification for the Use of Statins in Prevention - an Intervention Trial Evaluating Rosuvastatin) trial. J Am Coll Cardiol. 2010;55:1266-1273.

340. Glynn RJ, Koenig W, Nordestgaard BG, Shepherd J, Ridker PM. Rosuvastatin for primary prevention in older persons with elevated C-reactive protein and low to average low-density lipoprotein cholesterol levels: exploratory analysis of a randomized trial. Ann Intern Med. 2010;152:488-496, W174.

341. Pearson TA, Mensah GA, Alexander RW, et al. Markers of inflammation and cardiovascular disease: application to clinical and public health practice: a statement for healthcare professionals from the Centers for Disease Control and Prevention and the American Heart Association. Circulation. 2003;107:499-511.

342. Ridker PM, MacFadyen JG, Børge G, Nordestgaard BG, et al. Rosuvastatin for primary prevention among individuals with elevated high-sensitivity C-reactive protein and $5 \%$ to $10 \%$ and $10 \%$ to $20 \%$ 10-year risk: implications of the Justification for Use of Statins in Prevention: an Intervention Trial Evaluating Rosuvastatin (JUPITER) Trial for "Intermediate Risk". Circ Cardiovasc Qual Outcomes. 2010;3: $447-452$.

343. Kones R. Recent advances in the management of chronic stable angina I: approach to the patient, diagnosis, pathophysiology, risk stratification, and gender disparities. Vasc Health Risk Manag. 2010;6: 635-656.

344. Ridker PM, Glynn RJ. The JUPITER Trial: Responding to the critics. Am J Cardiol. 2010;106:1351-1356.

345. Harrington R, Ridker PM. The Bob Harrington Show. Episode \#26: Dissecting the controversy around JUPITER with Dr Paul Ridker. http://radio.theheart.org/bob-harrington-show/2010/8/20/episode-26dissecting-the-controversy-around-jupiter-with-dr-paul-ridker. 2010 Aug 27.

346. http://www.fda.gov/downloads/AdvisoryCommittees/Commit teesMeetingMaterials/Drugs/EndocrinologicandMetabolicDrugs AdvisoryCommittee/UCM193831.pdf. (FDA memorandum, 2009 Nov 12, Appendix, page 11). Accessed 2010 Oct 7.

347. Friedlin B, Korn E. Stopping clinical trials early for benefit: impact on estimation. Clin Trials. 2009;6:119-125.

348. Korn EL, Friedlin B, Mooney M. Stopping or reporting early for positive results in randomized clinical trials: the National Cancer Institute Cooperative Experience from 1990 to 2005. J Clin Oncol. 2009;27:1712-1721.

349. Bruckert E, Hayem G, Dejager S, et al. Mild to moderate muscular symptoms with high-dosage statin therapy in hyperlipidemic patients: the PRIMO study. Cardiovasc Drugs Ther. 2005;19: 403-414.

350. Hsu I, Spinler SA, Johnson NE. Comparative evaluation of the safety and efficacy of HMG-CoA reductase inhibitor monotherapy in the treatment of primary hypercholesterolemia. Ann Pharmacother. 1995;29:743-759.

351. Garcia-RodriguezLA, Masso-GonzalezEL, Wallander MA, Johansson S. The safety of rosuvastatin in comparison with other statins in over 100,000 statin users in UK primary care. Pharmacoepidemiol Drug Saf. 2008;17:943-952.

352. Garcia-Rodriguez LA, Gonzalez-Perez A, Stang MR, et al. The safety of rosuvastatin in comparison with other statins in over 25,000 statin users in the Saskatchewan Health Databases. Pharmacoepidemiol Drug Saf. 2008;17:953-961.

353. Sukhija R, Prayaga S, Marashdeh M, et al. Effect of statins on fasting plasma glucose in diabetic and nondiabetic patients. J Investig Med. 2009;57:495-499.

354. Koh KK, Quon MJ, Han SH, Lee Y, Kim SJ, Shin EK. Atorvastatin causes insulin resistance and increases ambient glycemia in hypercholesterolemic patients. J Am Coll Cardiol. 2010;55: 1209-1216. 
355. Kostapanos MS, Milionis HJ, Agouridis AD, Rizos CV, Elisaf MS. Rosuvastatin treatment is associated with an increase in insulin resistance in hyperlipidaemic patients with impaired fasting glucose. Int J Clin Pract. 2009;63;1308-1313.

356. Cholesterol Treatment Trialists' (CTT) Collaborators. Efficacy of cholesterol-lowering therapy in 18,696 people with diabetes in 14 randomised trials of statins: a meta-analysis. Lancet. 2008;371: 117-125.

357. Sattar N, Preiss D, Murray HM, et al. Statins and risk of incident diabetes: a collaborative meta-analysis of randomised statin trials. Lancet. 2010;375:735-742.

358. Baker WL, Talati R, White CM, Coleman CI. Differing effect of statins on insulin sensitivity in non-diabetics: a systematic review and meta-analysis. Diab Res Clin Pract. 2010;87:98-107.

359. Zhang FL, Casey PJ. Protein prenylation: molecular mechanisms and functional consequences. Annu Rev Biochem. 1996;65;241-269.

360. Takai Y, Sasaki T, Matozaki T. Small GTP-binding proteins. Physiol Rev. 2001;81:153-208.

361. Greenwood J, Steinman L, Zamvil SS. Statin therapy and autoimmune disease: from protein prenylation to immunomodulation. Nature Rev Immunol. 2006;6:358-370.

362. Chakrabarti R, Engleman EG. Interrelationships between mevalonate metabolism and the mitogenic signaling pathway in T lymphocyte proliferation. J Biol Chem. 1991;266:12216-12222.

363. Graham I, Atar D, Borch-Johnsen K, et al; Fourth Joint Task Force of the European Society of Cardiology and Other Societies on Cardiovascular Disease Prevention in Clinical Practice (Constituted by representatives of nine societies and by invited experts). European guidelines on cardiovascular disease prevention in clinical practice: executive summary. Eur Heart J. 2007;28:2375-2414.

364. Liu PY, Chen JH, Lin LJ, Liao JK. Increased Rho kinase activity in a Taiwanese population with metabolic syndrome. $\mathrm{J} \mathrm{Am} \mathrm{Coll} \mathrm{Cardiol.}$ 2007;49:1619-1624

365. Liao JK. Does it matter whether or not a lipid-lowering agent inhibits Rho kinase? Curr Atheroscler Rep. 2007;9:384-388.

366. Dong M, Yan BP, Liao JK, Lam YY, Yip GWK, Yu C-M. Rho-kinase inhibition: a novel therapeutic target for the treatment of cardiovascular diseases. Drug Discov Today. 2010;15:622-629.

367. Brozinick JT Jr, Berkemeier BA, Elmendorf JS. “Acting” on GLUT4: membrane and cytoskeletal components of insulin action. Curr Diabetes Rev. 2007;3:111-122.

368. Horvath EM, Tackett L, Elmendorf JS. A novel membrane-based anti-diabetic action of atorvastatin. Biochem Biophys Res Commun. 2008;372:639-643.

369. Nakata M, Nagasaka S, Kusaka I, Matsuoka H, Ishibashi S, Yada T. Effects of statins on the adipocyte maturation and expression of glucose transporter 4 (SLC2A4): implications in glycemic control. Diabetologia. 2006;49:1881-1892.

370. White CM. A review of the pharmacologic and pharmacokinetic aspects of rosuvastatin. J Clin Pharmacol. 2002;42:963-970.

371. Mita T, Watada H, Nakayama S, et al. Preferable effect of pravastatin compared to atorvastatin on beta cell function in Japanese early-state type 2 diabetes with hypercholesterolemia. Endocr J. 2007;54: 441-447.

372. Yada T, Nakata M, Shiraishi T, Kakei M. Inhibition by simvastatin, but not pravastatin, of glucose-induced cytosolic $\mathrm{Ca} 2+$ signaling and insulin secretion due to blockade of L-type $\mathrm{Ca} 2+$ channels in rat islet b-cells. Br J Pharmacol. 1999;126:1205-1213.

373. Siddals KW, Marshman E, Westwood M, Gibson JM. Abrogation of insulin-like growth factor-I (IGF-I) and insulin action by mevalonic acid depletion: synergy between protein prenylation and receptor glycosylation pathways. J Biol Chem. 2004;279:38353-38359.

374. Otokozawa S, Ai M, van Himbergen T, et al. Effects of intensive atorvastatin and rosuvastatin treatment on apolipoprotein B-48 and remnant lipoprotein cholesterol levels. Atherosclerosis. 2009;205: 197-201.
375. American Diabetes Association. Standards of Medical Care in Diabetes - 2009. Diabetes Care. 2009;32(Suppl 1):S13-S61.

376. Pasternak RC, Smith SC, Bairey-Merz CN, Grundy SM, Cleeman JI, Lenfant C. ACC/AHA/NHLBI clinical advisory on the use and safety of statins. Stroke. 2002;33:2337-2341.

377. Thompson PD, Clarkson P, Karas RH. Statin-associated myopathy. JAMA. 2003;289:1681-1690.

378. Tomlinson SS, Mangione KK. Potential adverse effects of statins on muscle. Phys Ther. 2005;85:459-465.

379. SEARCH Collaborative Group, Link E, Parish S, Armitage J, et al. SLCO1B1 variants and statin-induced myopathy - a genomewide study. N Eng J Med. 2008;359:789-799.

380. Gomes MD, Lecker SH, Jagoe RT, Navon A, Goldberg AL. Atrogin-1, a muscle-specific F-box protein highly expressed during muscle atrophy. Proc Natl Acad Sci U S A. 2001;98:14440-14445.

381. Hanai J, Cao P, Tanksale P, et al. The muscle-specific ubiquitin ligase atrogin-1/MAFbx mediates statin-induced muscle toxicity. $J$ Clin Invest. 2007;117:3940-3951.

382. Cao P, Hanai J-i, Tanksale P, Imamura S, Sukhatme VP, Lecker SH. Statin-induced muscle damage and atrogin-1 induction is the result of a geranylgeranylation defect. FASEB J. 2009;23: 2844-2854.

383. Knauer MJ, Urquhart BL, Meyer zu Schwabedissen HE, et al. Human skeletal muscle drug transporters determine local exposure and toxicity of statins. Circ Res. 2010;106:297-306.

384. Dorajoo R, Pereira BP, Yu Z, et al. Role of multidrug resistanceassociated protein-1 transporter in statin-induced myopathy. Life Sci. 2008;82:823-830.

385. Masters BA, Palmoski MJ, Glint OP, Gregg RE, Wang-Iverson D, Durham SK. In vitro myotoxicity of the 3-hydroxy-3-methylglutaryl coenzyme A reductase inhibitors, pravastatin, lovastatin, and simvastatin, using neonatal rat skeletal myocytes. Toxicol Appl Pharmacol. 1995;131:163-174.

386. Thalacker-Mercer A, Baker M, Calderon C, Bamman M. Simvastatin Reduces Human Primary Satellite Cell Proliferation in Culture. Presentation, American Physiological Society, The Integrative Biology of Exercise V. 2008 Sep 24-27, Hilton Head, SC. http://www.the-aps. org/press/journal/08/32.htm and http://www.the-aps.org/Video/Clips/ AnnaThalacker-Mercer.htm. Accessed 2010 Nov 20.

387. Marcoff L, Thompson PD. The role of coenzyme Q10 in statinassociated myopathy: a systematic review. $\mathrm{J} \mathrm{Am} \mathrm{Coll} \mathrm{Cardiol.}$ 2007;49:2231-2237.

388. Dirks AJ, Jones KM. Statin-induced apoptosis and skeletal myopathy. Am J Physiol Cell Physiol. 2006;291:C1208-C1212.

389. Sirvent P, Mercier J, Lacampagne A. New insights into mechanisms of statin-associated myotoxicity. Curr Opin Pharmacol. 2008;8:333-338.

390. Needham M, Fabian V, Knezevic W, et al. Progressive myopathy with upregulation of MHC-I associated with statin therapy. Neuromuscul Disord. 2007;17:194-200.

391. Grable-Esposito P, Katzberg HD, Greenberg SA, et al. Immunemediated necrotizing myopathy associated with statins. Muscle Nerve. 2010;41:185-190.

392. Vaklavas C, Chatzizisis YS, Ziakas A, Zamboulis C, Giannoglou GD. Molecular basis of statin-associated myopathy. Atherosclerosis. 2009; 202:18-28.

393. Mas E, Mori TA. Coenzyme Q10 and statin myalgia: what is the evidence? Curr Atheroscler Rep. 2010;12;407-413.

394. Vandenberg BF, Robinson J. Management of the patient with statin intolerance. Curr Atheroscler Rep. 2010;12:48-57.

395. Mammen AL, Amato AA. Statin myopathy: a review of recent progress. Curr Opin Rheumatol. 2010;22:644-650.

396. Thompson PD, Clarkson PM, Rosenson RS. An assessment of statin safety by muscle experts. Am J Cardiol. 2006;97:69C-76C.

397. Armitage J. The safety of statins in clinical practice. Lancet. 2007;370:1781-1790. 
398. Ford ES, Li C, Zhao G, Tsai J. Trends in obesity and abdominal obesity among adults in the United States from 1999-2008. Int J Obes (Lond). 2010 Sep 7. [Epub ahead of print].

399. Filion KB, Genest J, Joseph L, et al. The metabolic syndrome and cardiovascular risk: a systematic review and meta-analysis. J Am Coll Cardiol. 2010;56:1113-1132.

400. DeMazumder D, Hasan RK, Blumenthal RS, Michos ED, Jones S. Should statin therapy be allocated on the basis of global risk or on the basis of randomized trial evidence? Am J Cardiol. 2010;106:905-909.
401. Nambi V, Ballantyne CM. "Risky Business": ten years is not a lifetime. Circulation. 2009;119:362-364.

402. Lloyd-Jones DM, Hong Y, Labarthe D, et al; American Heart Association Strategic Planning Task Force and Statistics Committee. Defining and setting national goals for cardiovascular health promotion and disease reduction: the American Heart Association's strategic Impact Goal through 2020 and beyond. Circulation. 2010 121:586-613.

403. Webster R, Heeley E. Perceptions of risk: understanding cardiovascular disease. Risk Management and Healthcare Policy. 2010:3:49-60.

\section{Publish your work in this journal}

Drug Design, Development and Therapy is an international, peerreviewed open-access journal that spans the spectrum of drug design and development through to clinical applications. Clinical outcomes, patient safety, and programs for the development and effective, safe, and sustained use of medicines are a feature of the journal, which has also been accepted for indexing on PubMed Central. The manuscript management system is completely online and includes a very quick and fair peer-review system, which is all easy to use. Visit http://www.dovepress.com/testimonials.php to read real quotes from published authors.

Submit your manuscript here: http://www.dovepress.com/drug-design-development-and-therapy-journal 